University of South Florida

DIGITAL COMMONS

Digital Commons @ University of

@ UNIVERSITY OF SOUTH FLORIDA

South Florida

\title{
Application of Wave-Theoretical Seismoacoustic models to the Interpretation of Explosion and Eruption Tremor Signals Radiated by Pavlof Volcano, Alaska
}

\author{
Milton A. Garces \\ University of Hawaii \\ Stephen R. McNutt \\ Universtiy of Alaska Fairbanks, smcnutt@usf.edu \\ Roger A. Hansen \\ Universtiy of Alaska Fairbanks \\ John C. Eichelberger \\ Universtiy of Alaska Fairbanks
}

Follow this and additional works at: https://digitalcommons.usf.edu/geo_facpub

Part of the Earth Sciences Commons

\section{Scholar Commons Citation}

Garces, Milton A.; McNutt, Stephen R.; Hansen, Roger A.; and Eichelberger, John C., "Application of WaveTheoretical Seismoacoustic models to the Interpretation of Explosion and Eruption Tremor Signals Radiated by Pavlof Volcano, Alaska" (2000). School of Geosciences Faculty and Staff Publications. 284. https://digitalcommons.usf.edu/geo_facpub/284

This Article is brought to you for free and open access by the School of Geosciences at Digital Commons @ University of South Florida. It has been accepted for inclusion in School of Geosciences Faculty and Staff Publications by an authorized administrator of Digital Commons @ University of South Florida. For more information, please contact digitalcommons@usf.edu. 


\title{
Application of wave-theoretical seismoacoustic models to the interpretation of explosion and eruption tremor signals radiated by Pavlof volcano, Alaska
}

\author{
Milton A. Garces ${ }^{1}$ \\ Infrasound Laboratory, Hawaii Institute of Geophysics and Planetology, University of Hawaii, Manoa
}

\author{
Stephen R. McNutt, Roger A. Hansen, and John C. Eichelberger \\ Alaska Volcano Observatory, Geophysical Institute, University of Alaska, Fairbanks
}

\begin{abstract}
Tremor and explosion signals recorded on September 29 during the Fall 1996 Pavlof eruption are interpreted using video images, field observations, and seismic data. Waveform analysis of tremor and explosions provided estimates of the melt's volcano-acoustic parameters and the magma conduit dimensions. Initial mass fractions of $0.25 \%$ water and $0.025 \%$ carbon dioxide in the melt can explain the resonance characteristics of the tremor and explosion pulses inferred from seismic data. The magma conduit is modeled as a three-section rectangular crack. We infer that the tremor-radiating region consists of the lowermost two sections, both with cross-sectional areas of $\sim 10 \mathrm{~m}^{2}$. The deeper section is $43 \mathrm{~m}$ long, with magma sound speed of $230 \mathrm{~m} / \mathrm{s}$, density of $2600 \mathrm{~kg} / \mathrm{m}^{3}$, and viscosity of $1.0 \times 10^{6} \mathrm{~Pa}$. The section above it, defined by the water nucleation depth, is $64 \mathrm{~m}$ long, with magma sound speed of $91 \mathrm{~m} / \mathrm{s}$, density of $2000 \mathrm{~kg} / \mathrm{m}^{3}$, and viscosity of $1.4 \times 10^{6} \mathrm{~Pa}$. An average magma flow velocity of $1.2 \mathrm{~m} / \mathrm{s}$, with superposed random oscillations, acts as the tremor source. Explosions are postulated to occur in the uppermost part of the magma conduit after water comes out of solution. The explosion source region consists of a $15 \mathrm{~m}$ long section, with cross-sectional area of $20 \mathrm{~m}^{2}$, sound speed of $51 \mathrm{~m} / \mathrm{s}$, density of $1000 \mathrm{~kg} / \mathrm{m}^{3}$, and viscosity of $1.5 \times 10^{3} \mathrm{~Pa} \mathrm{~s}$. A burst pressure of $220 \mathrm{MPa}$ at $14 \mathrm{~m}$ depth would generate an acoustic pulse whose amplitude and character match the observed signal. Waveform analysis of the explosion pulses shows that the explosive event may be preceded by a long-period fluid transient which may trigger the metastable magma-gas mixture. The modeling procedure illustrates the synergy of fluid dynamic, seismic, and acoustic models and data with geological and visual observations.
\end{abstract}

\section{Introduction}

In July 1996, the Alaska Volcano Observatory (AVO) deployed a network of 12 short-period seismometers and one differential pressure sensor to monitor Pavlof volcano, located on the southwestern tip of the Alaska Peninsula (Figure 1). Pavlof is the most active volcano in North America and has produced $\sim 40$ eruptions since 1760 , most of them with a volcano explosivity index of 2-3 [Simkin and Siebert, 1994]. Interrupting the period of quiescence following its May 1988 eruption, Pavlof spawned a swarm of low-amplitude B-type events on September 11, 1996. The first strong seismic event occurred on September 15 at 1017 UT, and visual confirmation of the eruption occurred on September 16 at 1135 LT [Neal, 1996; J. Painter, personal communication, 1996]. Seasonal eruption patterns at Pavlof such as the fall 1996 eruption can be attributed to McNutt and Beavan's [1987] theory of ocean loading; a more detailed review of

${ }^{1}$ Also at the Geophysical Institute, University of Alaska, Fairbanks

Copyright 2000 by the American Geophysical Union.

Paper number 1999JB900096.

0148-0227/00/1999JB900096\$09.00
Pavlofs historical activity is given by McNutt [1987]. The most useful information from the perspective of monitoring was derived from the tremor and explosion signals recorded by six local seismic stations (Figure 1) and from satellite images. A pressure sensor was installed $40 \mathrm{~km}$ away from Pavlof, a distance which proved to be too large to detect any pressure signals associated with the relatively mild eruptive activity. During a helicopter flyby of Pavlof on September 29, 1996, S. McNutt and G. Tytgat of the AVO recorded video images of the eruption and made visual observations of the ash plume elevations. This additional information is used to further constrain estimates for the source characteristics, magma properties, and magma conduit dimensions inferred from analysis of the seismic and acoustic signals.

The work presented herein seeks to integrate existing theoretical models for the interpretation of seismic signals associated with the eruption of Pavlof volcano. These signals are assumed to be excited by (1) acoustic resonance of the magmatic conduit, which is in turn driven by hydrodynamic fluid processes, and (2) explosions in the conduit which propagate in the atmosphere as sound waves and couple into the ground. Because of the dependence of the seismic wave field on acoustic processes the signals analyzed in this paper are called seismo-acoustic signals. Throughout this paper, the linear theory of elasticity is used to derive analytical models 


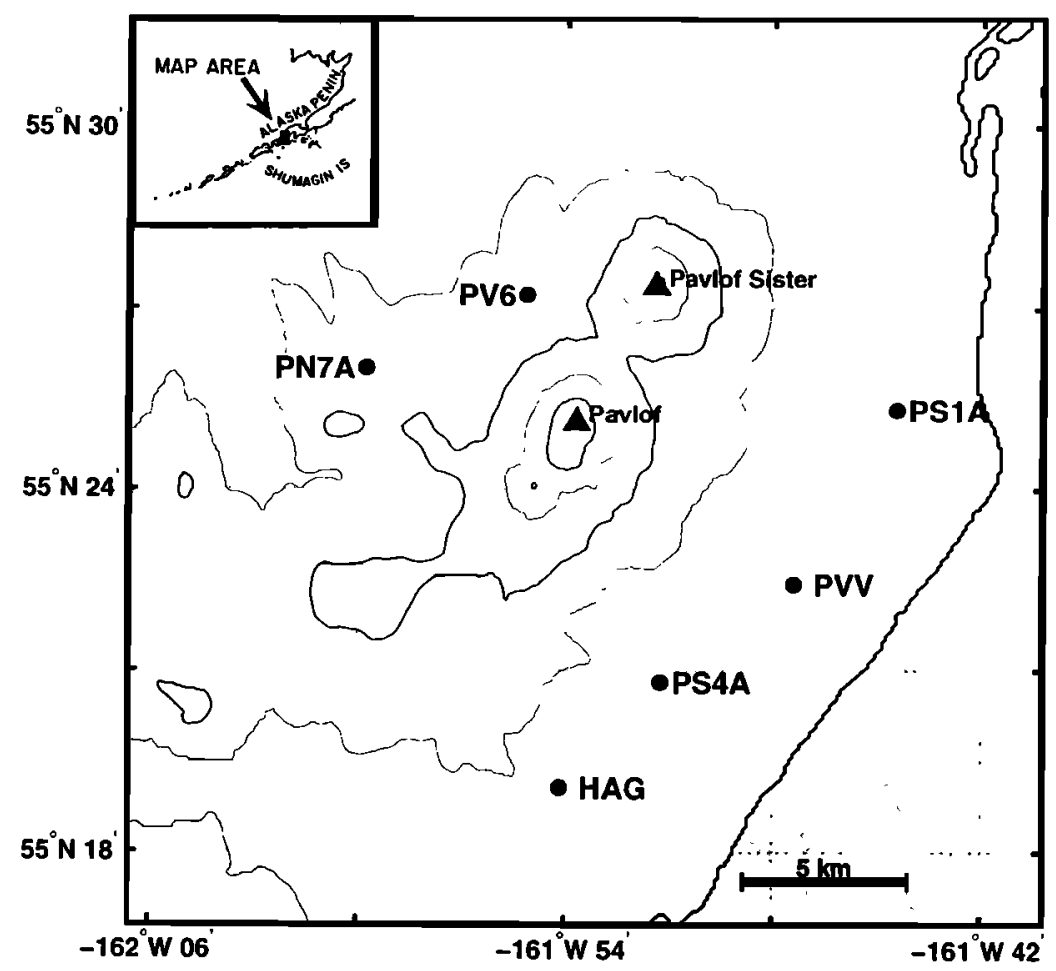

Figure 1. AVO seismic network installed in June-July 1996 around Pavlof volcano, Alaska. All stations have $1 \mathrm{~Hz}$ vertical geophones except for PV6, which has a $2 \mathrm{~Hz}$, three-component seismometer. A differential pressure sensor is in King Cove, $40 \mathrm{~km}$ away from the volcano. An absolute pressure sensor was installed at station PN7A in July 1997.

that allow the evaluation of seismic and acoustic fields in the ground, magma, and atmosphere. Without doubt, nonlinearities exist in the generation and propagation of these waves. However, it is desirable to understand the linear response of a physical system (which may be complicated) before it is possible to identify those effects which are due to nonlinearity.

This paper presents a pilot study on the feasibility of synthesizing acoustic, seismic, fluid dynamic, and geochemical models to interpret volcanic eruptions, and it will be shown that such a study will involve a large number of free parameters, which may possess significant uncertainties. The estimates provided by this work may vary by an order of magnitude, as neither the present quality of the models nor the quality of the data permit much greater accuracy. The accuracy of the models is limited by (1) implementation of only three layers to model a stratified magma conduit, (2) neglect of the flow velocity of the melt, (3) uncertainties in the values of viscosity and gas content of the melt, (4) lack of understanding of the behavior of magma and the physics of explosions at high void fractions, and (5) ignorance of path effects for seismic and acoustic waves. With the present models, our interpretation of the volcanic interior at Pavlof is valuable in the sense that, if the same geometry for the magma conduit is utilized, then it is possible to observe relative changes in the melt composition with respect to the initial model parameters. The analysis presented in this work highlights the fundamental physics of sound propagation in a stratified magma conduit and provides valuable insights that will be used in the development of the next generation of models. The wave-theoretical models assure uniqueness for prescribed material properties and boundary conditions [Graff, 1991], and the solutions can be evaluated rapidly. With the advent of improved recording and analysis systems it may be possible to produce accurate estimates of the volcanic interior in real time and to make forecasts based on these estimates. This paper directs further research in that direction.

\section{Salient Features of the Pavlof Data}

Seismic traces corresponding to the time of the September 29, 1996, helicopter flyby of Pavlof are shown in Figure 2. Tremor is manifest as a continuous background vibration of the ground, while sporadic explosion pulses (Figure 3) can be recognized by the increasing arrival time difference between the ground wave and the air wave with increasing distance. The air wave is the seismic recording of an acoustic wave propagating along the ground-air interface, and it can be identified by its sonic propagation velocity [McNutt, 1986] and its broader bandwidth. Some of the features of Pavlof explosions are presented by Garces and Hansen [1998], who focused on the distinction between the tremor and explosion source regions. Spectral analysis of all stations in Figure 2 showed a background tremor frequency with most of the energy between 1 and $2 \mathrm{~Hz}$. Other peaks in the spectra of tremor signals are attributed to seismic propagation effects and scattering, since adding together all the eruption spectra from all the stations did not reinforce any of these higherfrequency peaks. These same peaks are prominent in the spectrograms when Pavlof is not erupting, so this fine spectral 


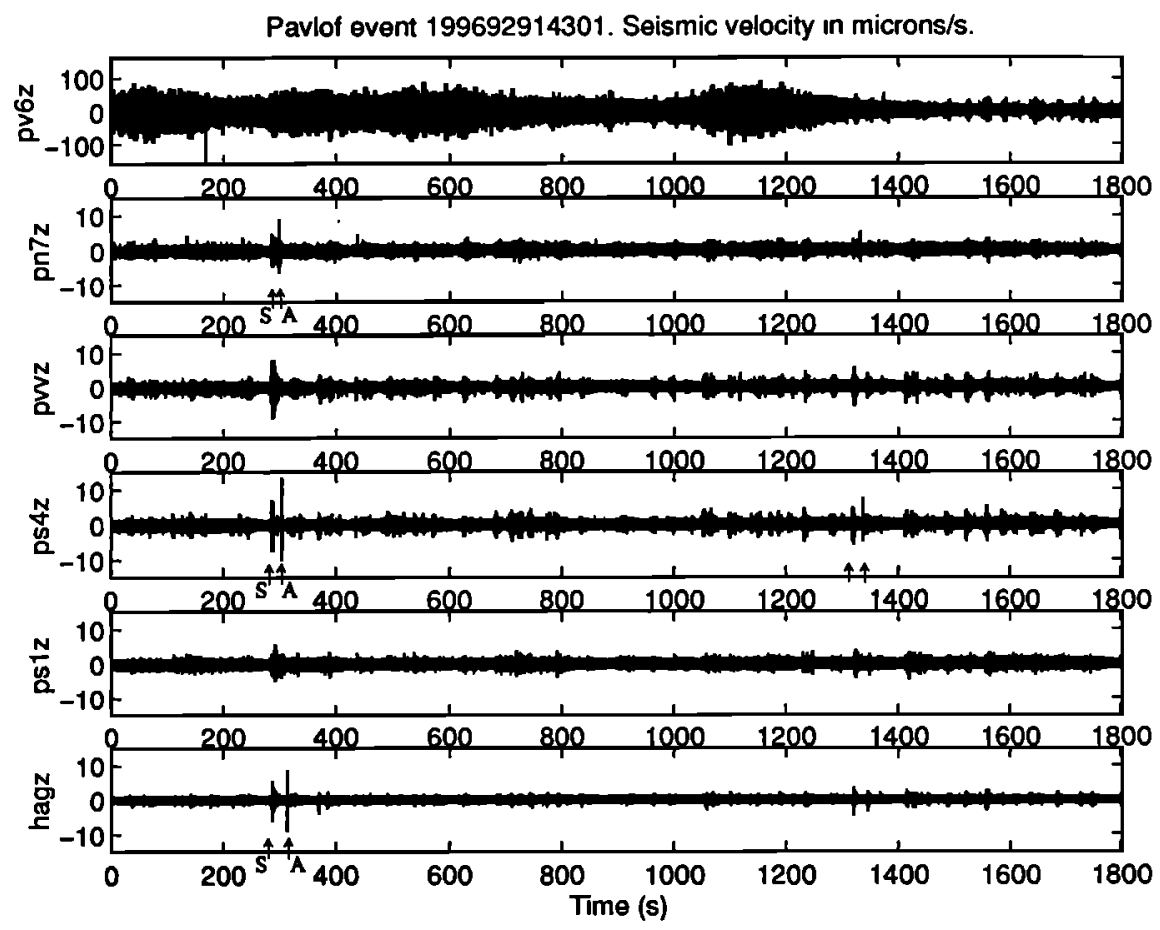

Figure 2. Vertical velocity component of the six seismic stations nearest to Pavlof volcano, aligned with increasing distance from the active vent. In addition to the continuous tremor and explosion signals observed at all stations, station PV6 also recorded signals associated with nearby surface flows. The direct seismic (S) and ground-coupled acoustic (A) pulses associated with explosions are marked by arrows. Note the different propagation velocities across the network for each phase.
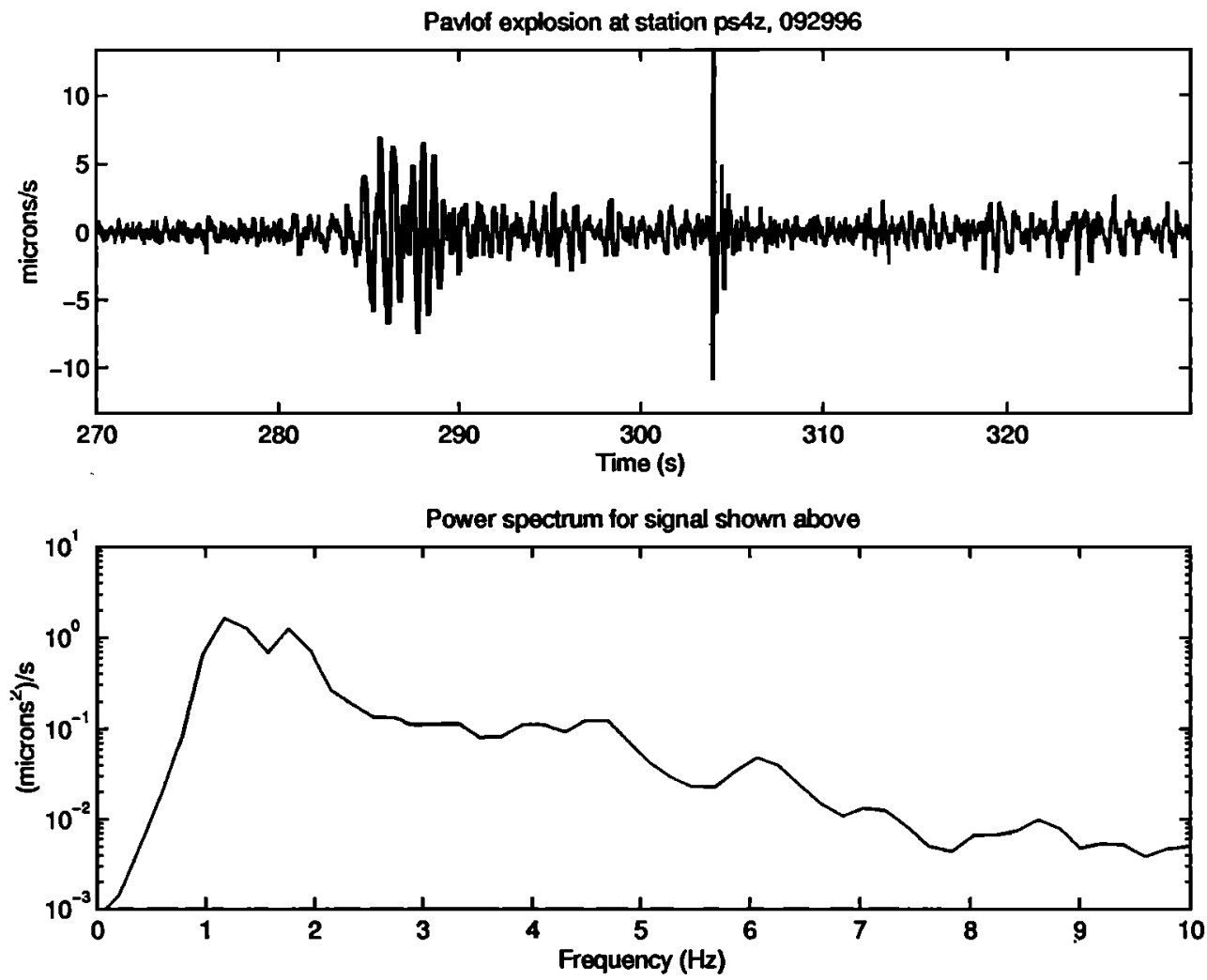

Figure 3. Pavlof explosion signal and its spectrum for station PS4. The spectrum was computed by using a sliding $5.12 \mathrm{~s}$ Hanning window with $50 \%$ overlap. Note the difference in the frequency content between the first phase and the ground-coupled air wave. 

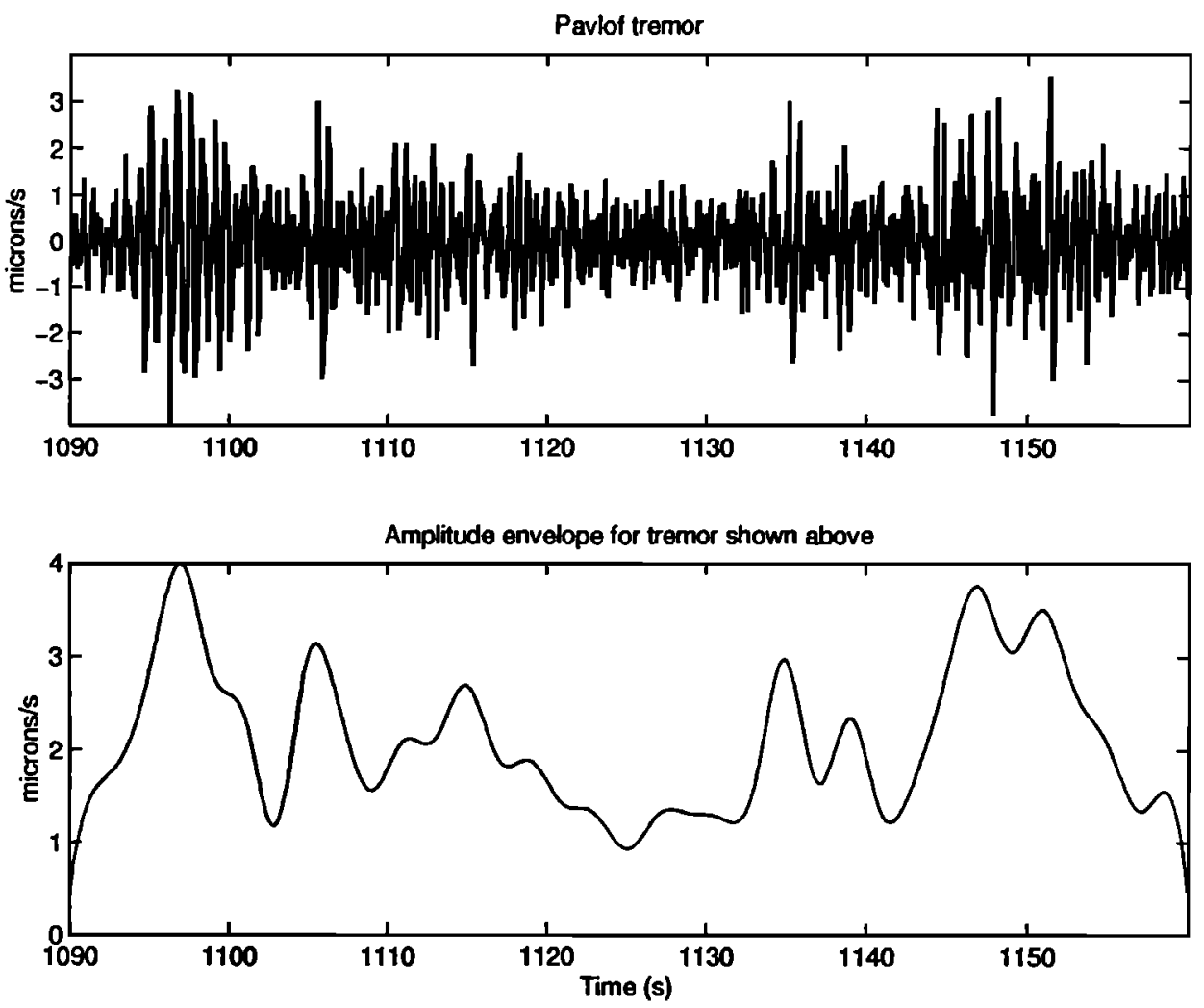

Figure 4. Pavlof tremor signal and its amplitude envelope for station PS4. The maximum value of the seismic amplitude in a sliding $1 \mathrm{~s}$ window was computed from the data to obtain the amplitude changes.

structure is evidently not related to volcanic source processes. In later sections, estimates for the dimensions and melt properties of the uppermost part of the magma conduit at Pavlof will be obtained from the interpretation of the eruption tremor and explosion signals recorded at station PS4.

Station PS4 was chosen as the reference because it has the highest air wave to tremor amplitude ratio of all the stations. This station was located in a protruding hill of tephra whose walls faced the summit of Pavlof, and this configuration may have accentuated the coupling of sound waves into the ground. Variations in the amplitude of the ground-coupled air wave at different sites may be due to the effects of the variable winds and differences in the transmission coefficients and incidence angles of the sound waves at different locations [Benoit et al., 1997; Garces et al., 1998b; Tahira, 1982]. The tremor signals are very similar for all the six nearest seismic stations, so we use only one station for the analysis of the tremor waveform and spectra. A typical segment of tremor is shown in Figure 4, and a clear explosion signal is shown in Figure 3. The explosion signal consists of two distinct phases; a long period arrival propagating through the ground ( $l \sim 282 \mathrm{~s})$ and a ground-coupled air wave ( $1 \sim 304 \mathrm{~s})$ traveling at sonic velocities. The first phase may be attributed to a fluid injection mechanism, as will be discussed in section 7. The goal of our analysis is to use the volcano-acoustic resonance (VOLAR) model [Garces, 1997; Garces and McNutt, 1997] shown in Figure 5 to generate waveform synthetics that match the temporal and spectral features of the waveforms shown in Figures 3 and 4. In its present state the VOLAR model has four general groups of parameters. These are defined by (1) magma composition, which defines the acoustic properties of the melt in the conduit, (2) lateral dimensions of the conduit, which are inferred from mass conservation and observed seismic and acoustic amplitudes, (3) source functions for tremor and explosions signals, which are constrained from plume heights and wave characteristics, and (4) propagation characteristics of acoustic waves in the magma and the atmosphere, seismic waves in the ground, and waves at the air-ground interface. We restrict the application of the models to seismic and acoustic signals which may be explained by the longitudinal resonance of a magma conduit. The first step in the modeling procedure is to identify the dominant frequency band and to select a reasonable conduit length and sound speed to match the observed resonance structure. The sound speed determines the void fraction and thus the density of the material, and the viscosity is selected to match the decay rate of explosion and tremor signals. The lateral dimensions are inferred from the conservation of mass along the conduit, which depends on the product of the density, flow speed, and cross-sectional area of the conduit. The density has been determined by the void fraction, the flow velocity can be constrained by the height of ejecta, and the total mass flux is estimated from lava flow volumes. Thus we can obtain estimates for the conduit area, which must be consistent with the observed radiation patterns and amplitudes of the recorded acoustic and seismic waves. Finally, we use specified source functions to match the amplitude and spectral envelope of the observed acoustic and seismic waves. The viscosity determines the width of the spectral peaks and the source spectrum acts as a band-pass filter on the conduit resonance 


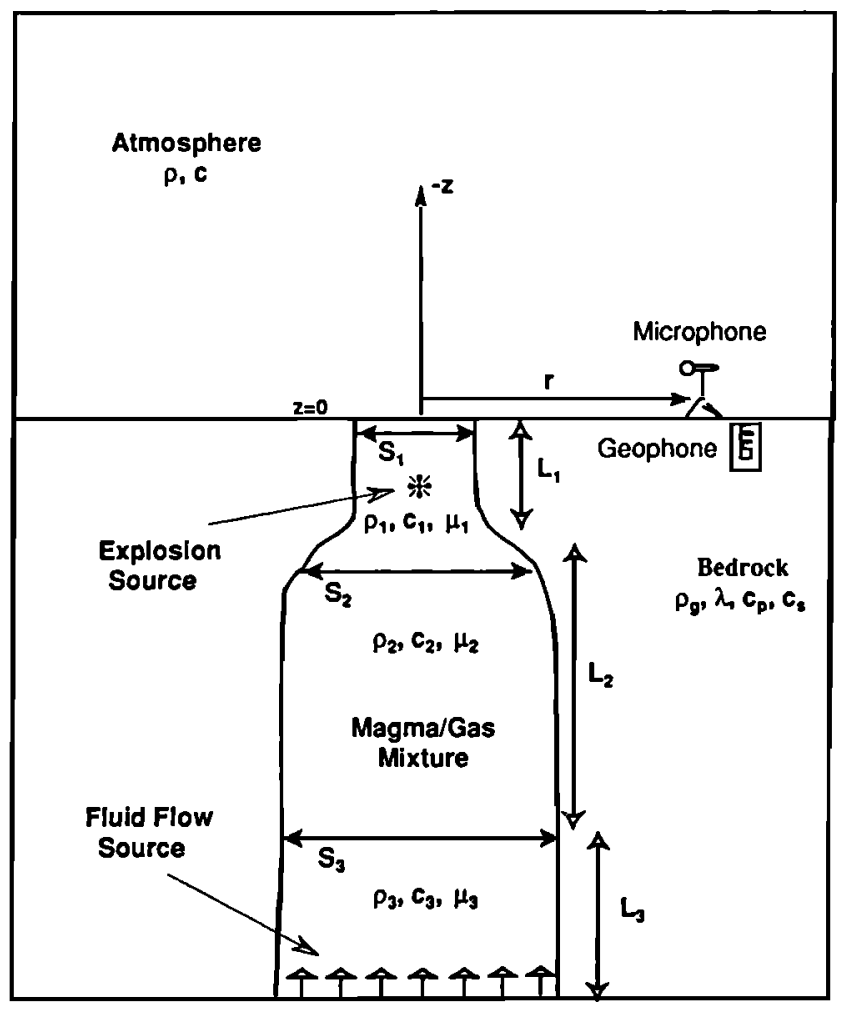

Figure 5. Geometry and physical parameters for the VOLAR model (not to scale). The magma conduit is divided into three sections ( $i=1,2,3$, from top to bottom), each with crosssectional area $S_{1}$ and length $L$, with a melt of density $\rho_{1}$, sound speed $c_{l}$, and viscosity $\mu_{l}$. An initial melt composition is prescribed at depth and determines the values of the density, sound speed, and viscosity for each section. A velocity field is imposed at the bottom of the conduit and excites the magma conduit into resonance. An explosive source in layer 1 may also ensonify this shallow layer. The sound field in the magma conduit propagates into the atmosphere through the open vent and radiates into the ground through the conduit wall. The airborne sound field is also coupled into the ground. The parameter values for the Pavlof model are give in Tables 1-3.

peaks. We then iterate the model parameters until the best visual fit between theory and data is found. This is a manual method of inverting for source functions and magma properties from observed seismic data, and although it is possible to automate such parameter iterations, the order-ofmagnitude accuracy of our estimates did not warrant such an effort. Ideally, the magma conduit dimensions would be stable in time, and we would know enough about the propagation characteristics of the acoustic and seismic waves that the inverse problem can be reduced to determinations of the melt composition and the source function characteristics. In sections 3-7, the results of matching the model's results to the waveforms shown in Figures 3 and 4 are discussed.

\section{Acoustic Properties of the Magma}

In this section we model the physical properties of the melt as a function of depth. The controlling factors are the magma composition and the gas content of the melt. As gas comes out of solution, the density, sound speed, viscosity, and flow velocity change significantly and affect the acoustic behavior of the melt. Unfortunately, the gas content of the melt is one of the most difficult pieces of information to extract accurately from a rock or magma sample. Yet, if the wave propagation and fluid flow models are sufficiently accurate, it may be possible to infer the gas content from observed seismic and acoustic signals.

Appendix A provides basic expressions for estimating the void fractions of $\mathrm{H}_{2} \mathrm{O}\left(\alpha_{1}\right)$ and $\mathrm{CO}_{2}\left(\alpha_{2}\right)$ gas as functions of depth in the magma conduit. Unfortunately, we did not have rock samples to extract these gas components at Pavlof. However, owing to groundwater contamination, the actual gas concentration on the upper hundred meters of a magma conduit may differ significantly from those inferred from geological samples, and we hope to estimate the gas concentrations from geophysical methods. Using the expressions given by Garces [1997], it is possible to infer the sound speed, density, viscosity, and relaxation time of the magma-gas mixture as functions of depth for given initial values. There is some controversy as to what the pressure profile in the magma column should be. On the one hand, the fluid pressure under flow will almost certainly differ from the magmatostatic pressure because of the imposed pressure gradient required for flow and the effects of viscosity [Papale and Dobran, 1994]. On the other hand, if the fluid pressure differs form the lithostatic pressure of the surrounding bedrock by $>20 \mathrm{MPa}$ [Albidirov and Dingwell, 1996], the conduit wall will collapse. For consistency, we will assume that the fluid pressure equilibrates with the lithostatic pressure and that the conduit remains open throughout the eruption. This assumption may push the fragmentation levels to shallower depths.

The following initial values for unvesiculated magma yielded a good match between theoretical and observed seismic waveforms: average melt temperature $T$ of $1473 \mathrm{~K}$, initial mass fraction of dissolved $\mathrm{H}_{2} \mathrm{O}\left(x_{1}{ }^{0}\right)$ of $0.25 \%$, initial mass fraction of dissolved $\mathrm{CO}_{2}\left(x_{2}{ }^{9}\right)$ of $0.025 \%$, dynamic viscosity of $1 \times 10^{6} \mathrm{~Pa} \mathrm{~s}$, density of $2700 \mathrm{~kg} / \mathrm{m}^{3}$, and sound speed of $2.5 \mathrm{~km} / \mathrm{s}$ [Murase and McBirney, 1973]. Assuming that the flow velocity of the magma is slow enough to allow equilibrium conditions, the magma is allowed to degas as it encounters the reduced pressure at reduced depth in the magma conduit. The equilibrium assumption is debatable, as recent seismo-acoustic measurements at Arenal Volcano suggest that equilibrium conditions may be disrupted during an eruption, leading to enhanced acoustic transmission of tremor energy into the atmosphere [Garces et al., 1998a]. However, in this paper we begin with the simplest models, which we will refine in future papers.

In a stratified magma column, any small flow may experience a net increase in velocity as it approaches the shallower levels of the conduit because of the decreasing density of the melt. The averaged flow speed of the magma column is estimated from the conservation of mass flux to be

$$
U=\frac{\rho_{i} U_{i} A_{i}}{\rho A},
$$

where $U_{l}, \rho_{i}$ and $A$, are the flow velocity, density, and crosssectional area of the fluid at the bottom of the magma conduit, respectively, and $U, \rho$, and $A$ are the flow velocity, density, and cross-sectional area, respectively, of the fluid above the bottom of the conduit. With the expressions presented herein 
(a) Total void fraction, $\%$

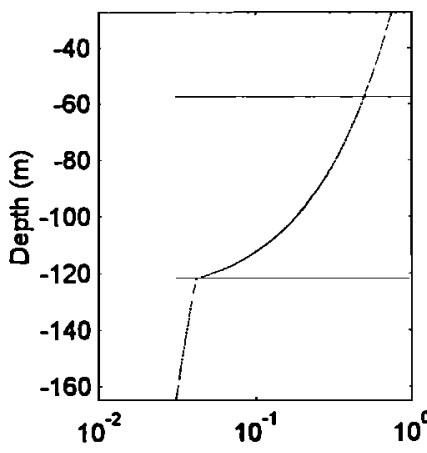

(d) Sound speed, $\mathrm{m} / \mathrm{s}$

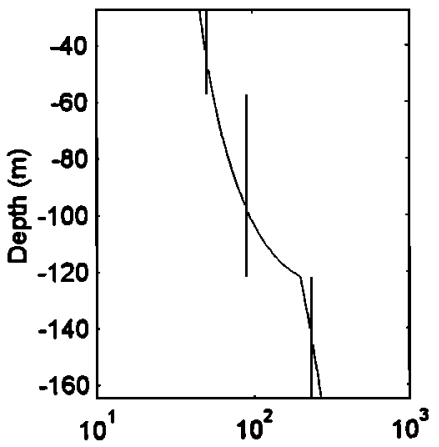

(b) Mixture density $\left(\mathrm{kg} / \mathrm{m}^{3}\right)$

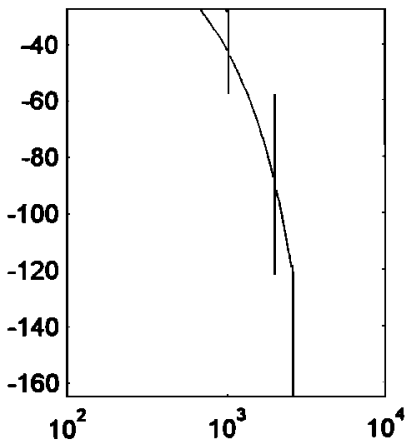

(e) Relaxation time, $s$

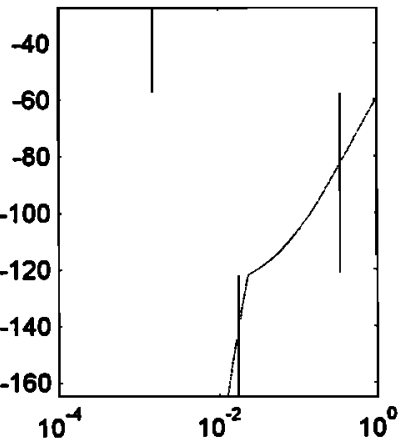

(c) Viscosity, Pa s

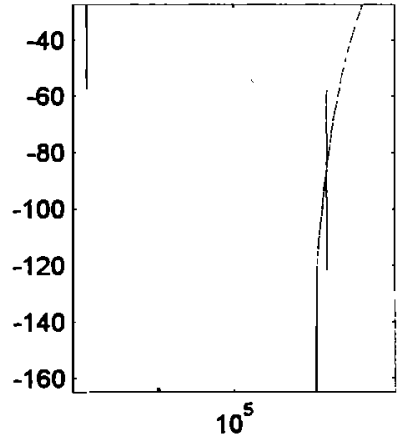

(f) Mach number

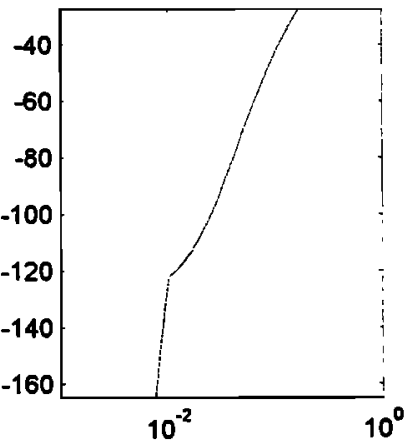

Figure 6. (a) Void fraction, (b) density, (c) dynamic viscosity, (d) sound speed, (e) relaxation time, and (f) flow Mach number as functions of depth for the Pavlof magma-gas mixture assuming an initial dissolved water mass fraction of $0.25 \%$ and an initial dissolved carbon dioxide mass fraction of $0.025 \%$. The horizontal lines demarcate the depths at which water comes out of solution and the $50 \%$ void fraction. The vertical lines show the average values used as input parameters to the models shown in Figure 7. Note that the inferred viscosity and relaxation time at the shallowest layer deviate from the predicted values. The unvesiculated magma viscosity is $1 \times 10^{6}$ pa $\mathrm{s}$, and the viscosity inferred from the explosion data is $1.5 \times 10^{3} \mathrm{pa} \mathrm{s}$. See text for further explanation.

and by Garces [1997], it is possible to estimate the void fraction, density, viscosity, sound speed, and flow velocity of the magma-gas mixture as functions of depth. These profiles are shown in Figure 6, where horizontal lines (Figure 6a) mark the estimated water exsolution depth (using equation (A20)) and the depth at which $50 \%$ void fraction is reached. At $75 \%$ void fraction we expect the foam to fragment [Sparks, 1978], so this level is considered to be part of the atmosphere, lacking any distinct upper boundary. The vertical lines (Figures 6b, 6c, 6d, and 6e) show the average values over these depths, which are used as input parameters for the VOLAR model shown in Figure 5. The modeling procedure consists of using the values given in Table 1 to compute the synthetic waveforms: $L_{1}$ is defined by the depth from $50 \%$ to $75 \%$ void fraction and is determined by the spectral structure of explosion signals; $L_{2}$ is defined by the water exsolution depth to the $50 \%$ void fraction and is determined by both the explosion and tremor spectra; and the bottom termination of $L_{3}$ is obtained by matching the observed tremor spectra to the model's predictions. Note that there is a sufficiently strong impedance contrast between the deepest and shallowest layers to acoustically decouple the explosion and tremor source regions [Garces and Hansen, 1998]. The initial values for the melt properties are iterated until a good visual fit to the data is obtained, and then the remaining model parameters are fine tuned to match the signal amplitudes and the bandwidth.
Under the assumption that the characteristic frequencies of each conduit section are determined by the acoustic resonance of the melt, the spectral structure of explosion, long-period, and tremor signals is determined at this stage of the modeling process.

Note that the values of viscosity and relaxation time used in the uppermost part of the conduit (Figure 6) differ from the theoretical values. The values for the viscosity were modified to match the explosion signal shown in Figure 3, and the modified relaxation time follows from this new value of the viscosity [Garces, 1997]. From the viscoelastic attenuation model of Garces [1997], when magma is excited at periods smaller than the relaxation time, the melt's behavior is more akin to a solid than to a liquid. The point of decreasing viscosity (uppermost vertical line in Figure 6c) corresponds to a relaxation period of $1 \mathrm{~s}$, when the background tremor signal can drive the magma into the brittle regime. This fact, coupled with the high vesicularity of an unstable foam close to the fragmentation level, may cause the melt to exhibit anomalous behavior. Thus the low effective viscosity value required by our model to match the explosion signals may indicate the need to implement more accurate models in this regime. All other values were determined from the formulation of Appendix A, and the only remaining free parameters are the conduit geometry and the source parameters. Sections 4-7 will address these model parameters in more detail. Note that the 
Table 1. Magma and Magma Conduit Parameters

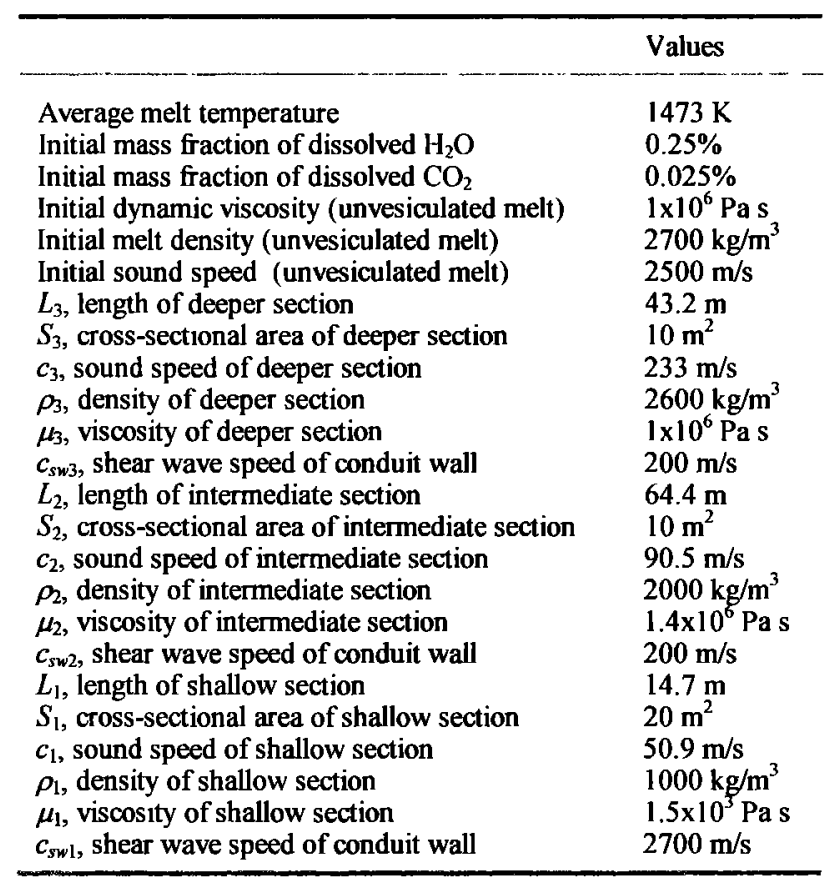

Mach number $M$ (the ratio of the flow velocity to the sound speed) always remains smaller than unity, as must be the case to justify the use of the linear theory of acoustics. One effect of the flow velocity will be to reduce the resonance frequency of the conduit by a factor (1-M $\left.{ }^{2}\right)$ [Morse and Ingard, 1986], which, for a resonant conduit, would be equivalent to reducing the sound speed by the same factor. Since we have not included the effects of the moving fluid into the present models, the sound speeds given in this work may be regarded as the equivalent sound speed $c_{\text {eff }}=\left(1-M^{2}\right) c$, where $c$ is the sound speed in a stationary medium.

The Vaisala-Brunt frequency is the maximum frequency of stable fluid oscillations under the force of gravity. For the depth $z$ decreasing downward, the Vaisala-Brunt frequency $N$ of the two-phase melt can be computed from [Lighthill, 1978]

$$
N(z)=\left[-\frac{g}{\rho(z)} \frac{\partial \rho}{\partial z}-\frac{g^{2}}{c(z)^{2}}\right]^{\frac{1}{2}},
$$

where $g$ is the gravitational acceleration. This quantity defines the cutoff frequency between gravity waves and acoustic waves, and for the values shown in Figure 6, the VaisalaBrunt frequency is plotted in Figure 7 as a function of depth. Only the real values are plotted, representing stable gravity oscillations. Figure 7 shows two distinct regions, the deeper determined by the exsolution of $\mathrm{CO}_{2}$ and the shallower by the exsolution of $\mathrm{H}_{2} \mathrm{O}$. Note that the Vaisala-Brunt frequency comes close to $1 \mathrm{~Hz}$, which is often considered to be the lowend cutoff frequency for tremor signals in volcanoes [McNutt, 1992].

\section{Ballistics and Plume Heights}

As mentioned in section 2 , the flow velocity and mass flux of the material in the conduit allow us to estimate the crosssectional area of the conduit. We use the height of ballistics to infer the flow velocity and the mass flux to calibrate the plume heights with the tremor amplitudes. We estimate the ballistic and plume heights from video images and the mass flux from historical and recent lava flows. The maximum height of ejecta $H_{b}$ is estimated from the initial velocity $u_{e}$ of the material,

$$
H_{b}=\frac{u_{e}^{2}}{2 g},
$$

and provides an estimate of the exit velocity. Video images showed that ballistic heights at Pavlof on September 29, 1996, were $100-200 \mathrm{~m}$ above the vent. Yet there are some complications involved in determining at what level do we consider the particles to be launched. If we assume that the pyroclasts are formed above the fragmentation level, then the density of the fluid is that of a pseudogas, which may be significantly lower than that of the unfragmented material below it. If so, from equation (1) the exit velocity may be much higher than that of the unfragmented melt. For the computation of the predicted ballistic heights from the flow source model presented in section 5 , the density of the magma-gas mixture just below the fragmentation level was used as a reference for estimating the density of the pseudogas. A fragmented to unfragmented density ratio of 0.1 was found to be consistent with the observed ballistic heights and estimated mass flux values at Pavlof.

The height of the volcanic plume is governed by the effects of buoyancy, and its final height $H_{P}$ is estimated from Wilson et al. [1978]:

$$
H_{P}=8.2(s \Delta T)^{\frac{1}{4}}\left(F \rho_{3} S_{3} u_{3}\right)^{\frac{1}{4}} .
$$

For the Pavlof eruption we used a specific heat capacity $s=$ $1100 \mathrm{~J} \mathrm{~kg}^{-1} \mathrm{~K}^{-1}$, a relatively low conversion efficiency of stored energy to thermal energy of $F=0.1$, and a temperature drop of $\Delta T=800 \mathrm{~K}$. Thus if we can prescribe the mass flux $\rho_{3} S_{3} u_{3}$ as a function of time, we can predict the temporal variation of the plume height. The mass flux can be extracted directly from the

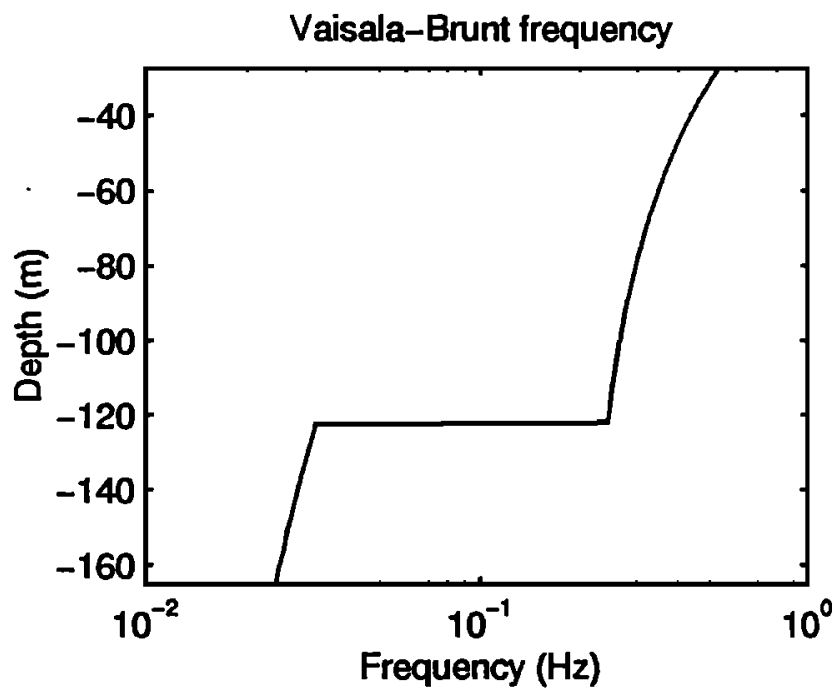

Figure 7. Vaisala-Brunt frequency as a function of depth for the magma conduit parameters shown in Figure 6. Two distinct regions are defined by the water exsolution level at $120 \mathrm{~m}$ depth. Sustained gravity wave oscillations may be used to study variations in the very-long-period quasi-steady flow of material in the conduit. 
tremor source mechanism which will be developed in section 5 , and thus we now have the means to relate tremor amplitudes to plume heights. Using an extruded lava volume of $6.5 \times 10^{5} \mathrm{~m}^{3}$ over a period of 13 days [McNutt and Bevan, 1987], as well as from estimates of the lava volumes during the 1996 eruption, the mean mass flux at Pavlof is estimated to be of the order of $10^{4} \mathrm{~kg} / \mathrm{s}$. The ash cloud elevation during the eruption of September 29, 1996, was observed to be 2 to 3 $\mathrm{km}$ above the vent. Since the mass flux model presented in section 5 relates the seismic amplitude of tremor to the steady mass flux rate, it may be possible to calibrate a given volcano for specified meteorological conditions so that the plume heights can be predicted from seismic observations during an eruption. Such estimates are of great value to aircraft safety during times of poor visibility where satellite images may be of limited assistance [Kamo et al., 1994].

\section{Acoustic Source Mechanisms}

We now develop mechanisms that can excite acoustic waves in the fluid within the magma conduit. These sound waves generate seismic waves in the ground through the displacement of the conduit wall. Two source mechanisms are implemented in this paper, a fluid dynamic source model and an explosive source model. The fluid flow model permits the generation of tremor and long-period signals, which may be directly associated with mass injection or removal at the bottom of the conduit, and permits estimates of time-varying plume and ballistic heights. The explosion source corresponds to a rapid expansion of gas or the detonation of an unstable magma-water mixture in the shallow part of the conduit, where there may be a region of sudden depressurization [Papale and Dobran, 1994]. Table 2 lists the source parameters used in this paper.

\subsection{Fluid Flow Model}

We wish to model the injection and extraction of material into a magma conduit and to relate this mass transfer to acoustic amplitudes in the fluid. The specification of the fluid velocity at the lower termination of the conduit allows flexibility in the source processes and the frequency bandwidths that may be studied [Garces, 1997]. The mass flux model of the velocity is

Table 2. Source Parameters

\begin{tabular}{ll}
\hline & Values \\
\hline Maximum long-period (LP) source flow velocity & $2.4 \mathrm{~m} / \mathrm{s}$ \\
Maximum speed of turbulent oscillations during LP & $1.7 \mathrm{~m} / \mathrm{s}$ \\
Average mass flux for LP & $3 \times 10^{4} \mathrm{~kg} / \mathrm{s}$ \\
Approximate duration of LP mass injection & $10 \mathrm{~s}$ \\
Maximum predicted ash cloud height during LP & $2700 \mathrm{~m}$ \\
Maximum predicted ash cloud height during LP & $140 \mathrm{~m}$ \\
Maximum tremor source flow velocity & $1.2 \mathrm{~m} / \mathrm{s}$ \\
Maximum speed of tremor source oscillations & $1.1 \mathrm{~m} / \mathrm{s}$ \\
Average mass flux for tremor & $2 \times 10^{4} \mathrm{~kg} / \mathrm{s}$ \\
Maximum predicted ash cloud height during tremor & $2200 \mathrm{~km}$ \\
Maximum predicted ash cloud height during tremor & $98 \mathrm{~m}$ \\
Equivalent moment tensor depth for tremor & $50 \mathrm{~m}$ \\
Explosion source pressure & $220 \mathrm{MPa}$ \\
Explosion source corner frequency & $7 \mathrm{~Hz}$ \\
Equivalent moment tensor depth for explosion & $14 \mathrm{~m}$ \\
\hline
\end{tabular}

$$
U(j \omega)=\frac{j \omega m(j \omega)}{\rho S_{3}},
$$

where $m(j \omega)$ is the Fourier transform of the time-varying mass injected or removed into the system. Equation 5 imposes conservation of mass. In the time domain, it is expressed as

$$
u=\frac{1}{\rho_{3} S_{3}} \frac{\partial m}{\partial t}
$$

so the vertical velocity is proportional to the rate of mass injection into the conduit. Thus oscillations in the mass flux passing through the conduit will generate pressure fluctuations in the magma.

An initial model for the velocity corresponds to an injection of magma, with source velocity function

$$
u(t)=u_{\max }\left(\frac{\gamma e}{n} t\right)^{n} e^{-t \gamma} \quad t>0,
$$

and Fourier transform

$$
U(j \omega)=u_{\max }\left(\frac{\gamma e}{n}\right)^{n} \frac{n !}{(y+j \omega)^{n+1}},
$$

where $n$ is an integer and $\gamma$ is an exponential decay constant. This model may represent a transient injection of material, which can generate the first phase shown in Figure 3. As discussed by Garces [1997], the total mass injected during this process is

$$
m_{1}=\rho_{3} S_{3} \frac{u_{\max }}{\gamma}\left(\frac{e}{n}\right)^{n} n !
$$

Equations (7)-(9) can also be used to model an extraction of material, in which case there is a sign change.

A flow field can be separated into steady, oscillatory, and turbulent components. A steady field will produce no sound waves, but a turbulent field can excite oscillations. We will now modify (9) by adding turbulence, represented by the superposition of a random component in the flow speed. Insertion of this source model into the wave equation yields the oscillatory component for the flow field. For Pavlof volcano we add random fluctuations to the initial velocity function and convolve with a filter,

$$
u(t)=\left\{\left[u_{\max }+u_{r} \Gamma(t)\left(\frac{\gamma e}{n} t\right)^{n} e^{-t r}\right\} * W_{b}(t),\right.
$$

where $u_{r}$ is a the amplitude of the random fluctuations, $\Gamma$ is uniformly distributed between -1 and 1 , and $W_{b}$ is a zerophase, second-order low-pass Butterworth filter [Oppenheim and Shafer, 1989]. For the computation of the theoretical waveforms for the first phase shown in Figure 3, $u_{\max }=2.4$ $\mathrm{m} / \mathrm{s}, \gamma=0.8, n=2, u_{r}=0.7 u_{\max }$, and the cutoff frequency of the low-pass filter is $4 \mathrm{~Hz}$. The corner frequency of the lowpass filter effectively removes the spatial and temporal scales of turbulence in the fluid flow which are too small contribute to the generation of tremor. The maximum velocity was chosen so that (3) and (4) would yield ballistic and plume heights consistent with observations. The constants $\gamma$ and $n$ were chosen to obtain the best fit to the spectral envelope. Finally, the fluctuation velocity was chosen to match the observed tremor amplitudes. From (9) the derived mass input is $\sim 2.9 \times 10^{5} \mathrm{~kg}$. Figure 8 shows the theoretical source function and its spectrum, and Figure 9 shows the predicted mass flux 

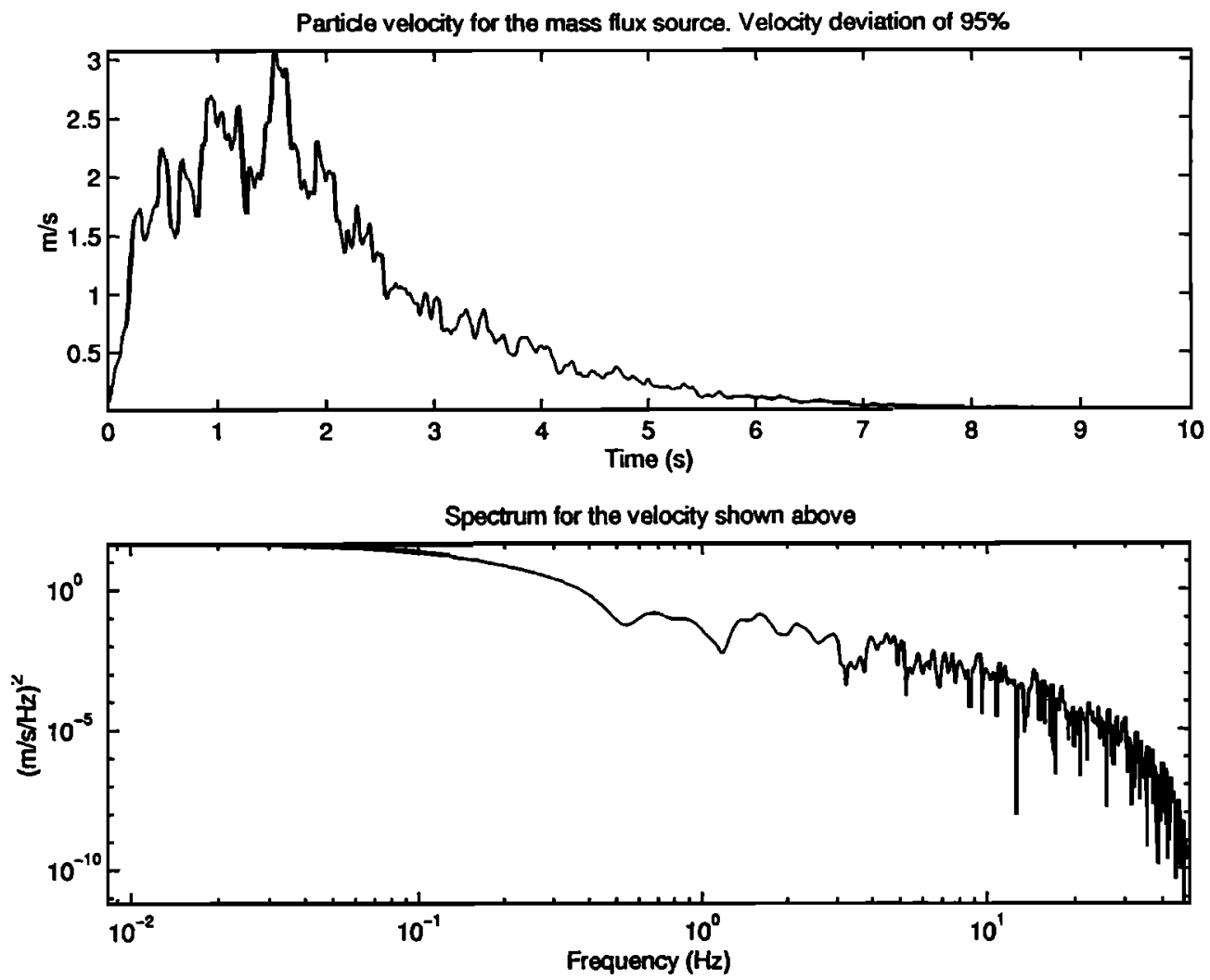

Figure 8. Source velocity function and its energy spectrum for the mass injection model at Pavlof. The spectrum was obtained from the absolute magnitude squared of the Fourier transform of the source-time function. The low-frequency characteristics of the ground wave associated with the explosions at Pavlof are attributed to the response of the magma conduit to this source excitation.

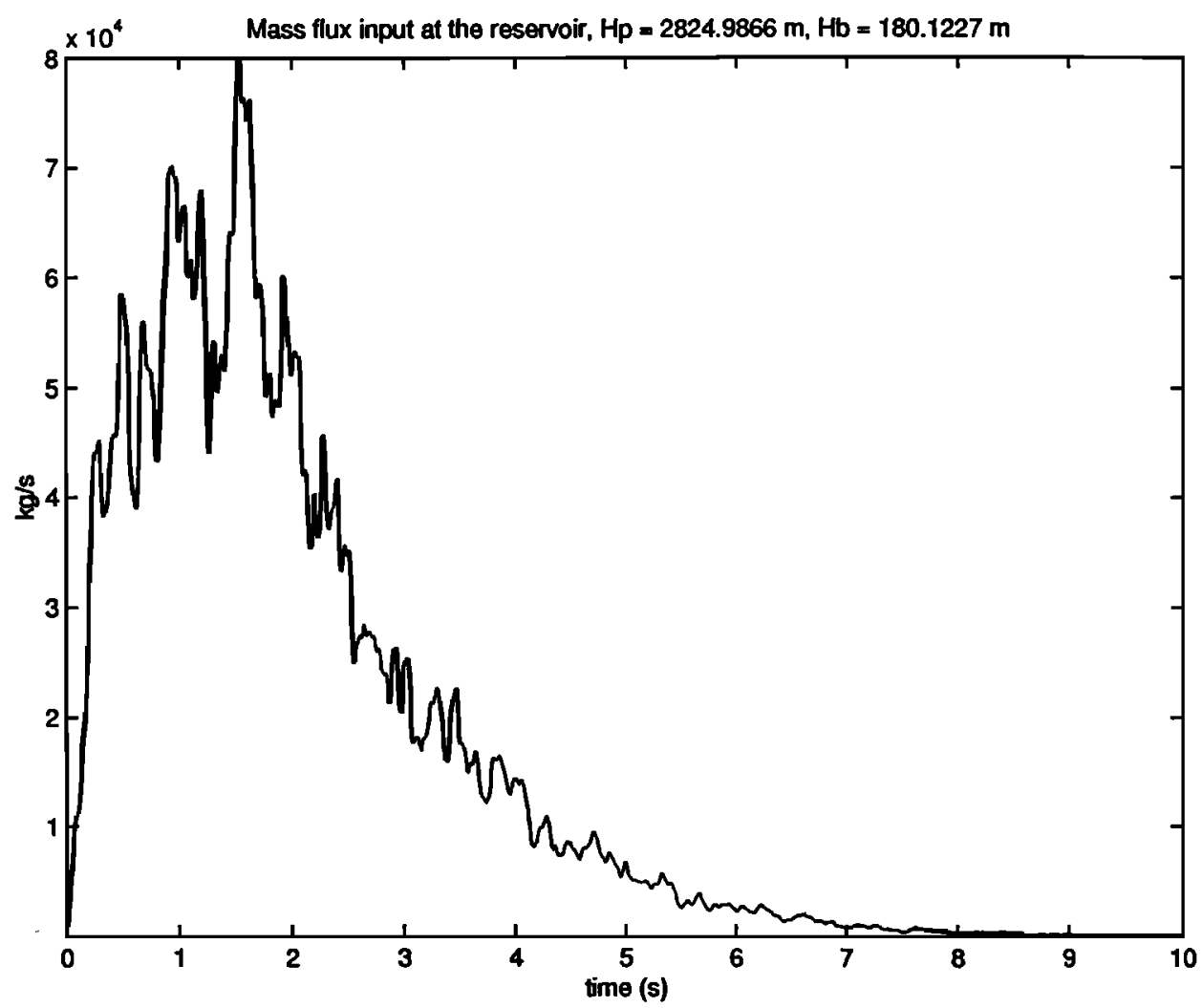

Figure 9. Mass flux input at the magma reservoir obtained from the mass flux model shown in Figure 8. The maximum ash cloud height is $2.8 \mathrm{~km}$, and the maximum ballistic height is $180 \mathrm{~m}$, in agreement with observations. 

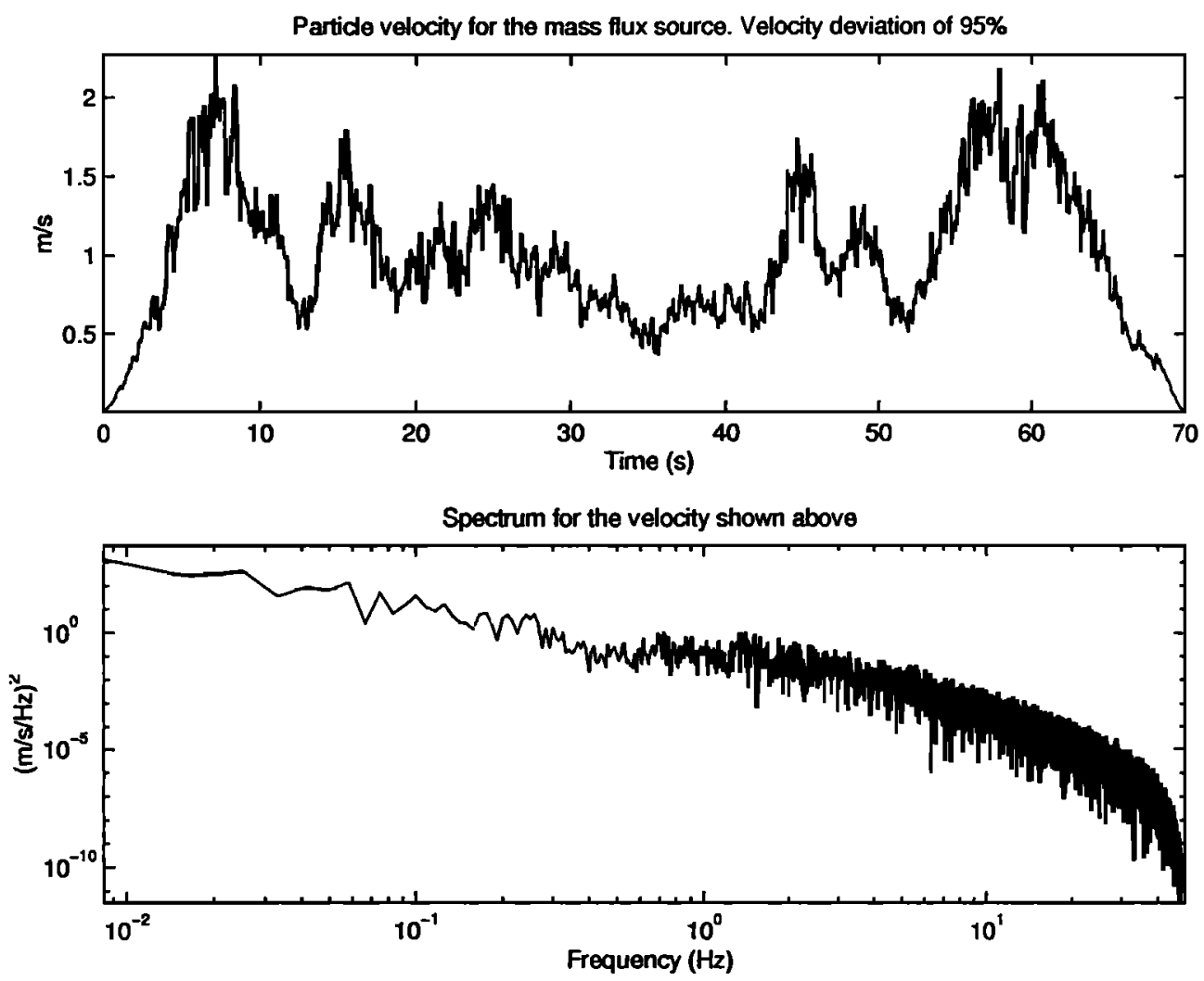

Figure 10. Source velocity function and its energy spectrum for the tremor source model at Pavlof. The spectrum was obtained from the absolute magnitude squared of the Fourier transform of the source-time function. Note that, as in Figure 8, the source function is quite rich in low frequencies and thus capable of exciting gravity waves and broadband seismic signals.

as a function of time. The predicted average mass flux of $3 \times 10^{4} \mathrm{~kg} / \mathrm{s}$ is consistent with the estimate of $10^{4} \mathrm{~kg} / \mathrm{s}$ measured from lava flow volumes. The maximum ash cloud and ballistic heights of $2.8 \mathrm{~km}$ and $180 \mathrm{~m}$, respectively, are consistent with visual observations obtained from the September 29, 1996, video of the Pavlof eruption.

For the tremor source, which is a sustained vibration and not a transient event, we used a similar approach but utilized the data itself to dictate the amplitude envelope of the source function. To obtain the source function amplitude, the maximum value of the seismic amplitude in a sliding $1 \mathrm{~s}$ window was extracted from the data to obtain the long-period amplitude changes. The resulting amplitude envelope is shown in Figure 4 (bottom). The normalized amplitude envelope $f(t)$ was then used to obtain the source velocity function,

$$
u=\left(u_{\max }+u_{r} \Gamma\right) f(t) * W_{b} .
$$

For the tremor amplitude, $u_{\max }=1.2 \mathrm{~m} / \mathrm{s}$ and $u_{r}=0.95 u_{\max }$, with the other source parameters being the same as those used for (10). Figure 10 shows the theoretical tremor source velocity function and its spectrum, obtained from (11), and Figure 11 shows the mass flux rate as a function of time. The average mass flux of $2 \times 10^{4} \mathrm{~kg} / \mathrm{s}$ and maximum ash cloud and ballistic heights of $2.2 \mathrm{~km}$ and $98 \mathrm{~m}$, respectively, are consistent with video taped observations of the Pavlof eruption. As expected, the ash cloud heights and ballistic elevations are lower than the transient mass injection source of Figure 9.

Because the source functions dictate the flow velocity at the bottom of the conduit, it is possible to estimate the mass flux of the magma and to constrain the cross-sectional area of the conduit from (1). The width and thickness of the conduit are also constrained by the seismic amplitudes [Garces, 1997]. From mass conservation and comparison of synthetic and observed seismic waveforms and spectra the width $W$ and thickness $d$ for the three sections of the conduit shown in Figure 5 are $W_{1}=5 \mathrm{~m}, d_{1}=4 \mathrm{~m}, W_{2}=10 \mathrm{~m}, d_{2}=1 \mathrm{~m}, W_{3}=$ $10 \mathrm{~m}, d_{3}=1 \mathrm{~m}$. These conduit dimensions provided the best fit to the amplitude of the seismic data and yielded flow velocities consistent with the observed ballistic and plume heights [Garces, 1997]. The effective tremor source depth was $50 \mathrm{~m}$ for all the model computations. The relatively shallow depth of the equivalent moment tensor may be attributed to the approximately conical topography of the volcano.

\subsection{Explosions}

Numerous explosions were observed at Pavlof (Figure 2), and we postulate that these explosions occur in the shallow, highly vesiculated part of the magma column where small pressure instabilities may trigger a metastable magma-gas mixture. The explosions may excite the upper section of the magma conduit into resonance [Buckingham and Garces, 


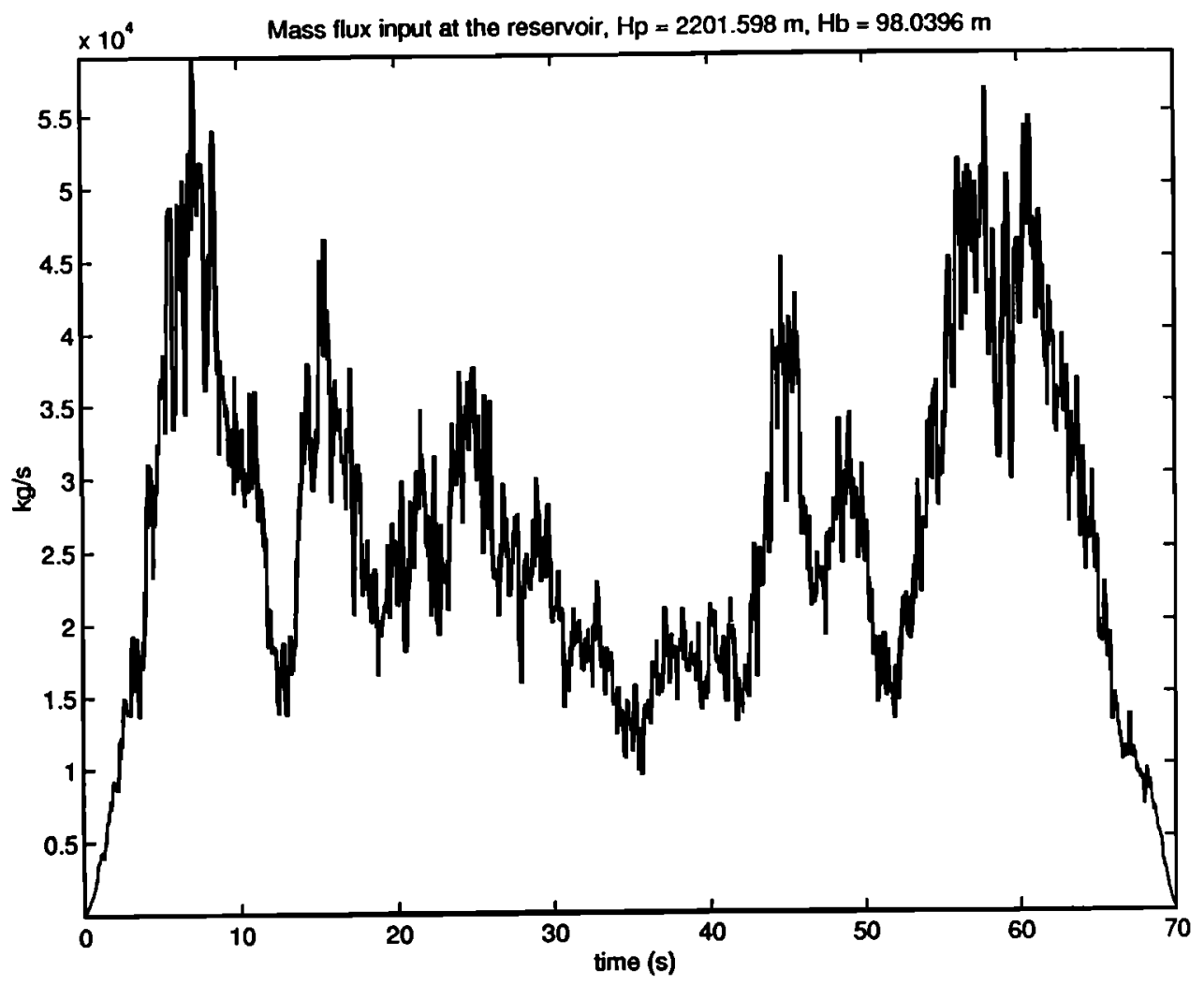

Figure 11. Mass flux input at the magma reservoir obtained from the mass flux model shown in Figure 10. The maximum predicted ash cloud height is $2.2 \mathrm{~km}$, and the maximum ballistic predicted height is $98 \mathrm{~m}$.

1996], which allows us to obtain estimates of the dimensions of the upper part of the conduit from the spectral structure of the radiated explosion signals. The source pressure function for the explosion is given by

$$
p_{s}(t)=p_{0}\left(1-\sqrt{2} \omega_{m} t+\frac{\omega_{m}^{2} t^{2}}{4}\right) \exp \left(-\frac{\omega_{m} t}{\sqrt{2}}\right) .
$$

where $p_{0}$ is the explosion pressure in pascals, $\omega_{m}$ is the angular corner frequency in radians per second, and $t$ is time in seconds. This explosive source model corresponds to a sudden gas bubble detonation akin to those encountered in underwater explosions. A description of the application of the explosive source model to the interpretation of volcanoseismic signals is by Garces and McNutt [1997]. The explosion source is used to investigate the resonance characteristics of the uppermost part of the conduit at Pavlof, where unstable magma-gas mixtures may detonate violently. For the signal shown in Figure 3 an explosion pressure $p_{0}=$ $220 \mathrm{MPa}$, a comer frequency $\omega_{m} /(2 \pi)=7 \mathrm{~Hz}$, and a source depth of $14 \mathrm{~m}$ yielded an acceptable visual fit to the data. Note that it is difficult to see a $7 \mathrm{~Hz}$ corner frequency in the data because the radiated spectrum is the product of the conduit resonance spectrum and the source spectrum. Yet the period of the first arrival is consistent with this corner frequency. The exact processes that create Strombolian explosions are still not clearly understood; however, once the energetics and properties of these explosions are known, the source function presented herein may be used to infer the amounts of detonated material and the conditions during the explosion [Garces and McNutt, 1997].

\section{Propagation Models}

To compare synthetic seismograms with observed data, we need propagation models for sound waves in a magma conduit, seismic waves in the ground, sound waves in the atmosphere, and sound waves from the atmosphere into the ground. The VOLAR model accounts for the acoustic resonance of the magma conduit and the coupling of this pressure field into the ground. The equivalent moment tensor for the conduit is derived and used to obtain synthetic seismic traces. The fluid velocity at the open vent is utilized to evaluate the airborne sound field, and the transmission coefficients of air to ground are used to evaluate the groundcoupled air wave. Table 3 lists the propagation parameters utilized in the modeling of the Pavlof signals.

Table 3. Propagation Model Parameters

\begin{tabular}{ll}
\hline & Values \\
\hline Recording station range & $8000 \mathrm{~m}$ \\
Volcanic rock density & $2700 \mathrm{~kg} / \mathrm{m}^{3}$ \\
Average rock P wave speed & $3000 \mathrm{~m} / \mathrm{s}$ \\
Average rock S wave speed & $1732 \mathrm{~m} / \mathrm{s}$ \\
Quality factor for P waves & 300 \\
Quality factor for S waves & 175 \\
Quality factor for Rayleigh waves & 45 \\
Surface tephra P wave speed & $1500 \mathrm{~m} / \mathrm{s}$ \\
Surface tephra S wave speed & $380 \mathrm{~m} / \mathrm{s}$ \\
Atmospheric density & $1 \mathrm{~kg} / \mathrm{m}^{3}$ \\
Atmospheric sound speed & $320 \mathrm{~m} / \mathrm{s}$ \\
\hline
\end{tabular}




\subsection{Volcano-Acoustic Resonance (VOLAR) Models}

This paper focuses on the seismo-acoustic field radiated by the longitudinal resonance of a rectangular magma conduit. Acoustic resonance is a propagation effect which may determine many of the spectral characteristics of acoustic and seismic signals recorded near active volcanoes. The parameters for the interior of the magma conduit are specified in Tables 1 and 2, and in this section we discuss the coupling of the internal pressure field into the surrounding rock. As presented by Garces [1997], in the low-frequency approximation the displacement of the rectangular conduit walls is in phase with the pressure, and thus a positive internal pressure corresponds to an outward displacement. This approximation is adequate if we consider only the longitudinal resonant modes of the conduit, but it is expected to break down when transverse modes are prominent. If transverse modes are present, then the wavenumber vector of the pressure waves in the conduit will no longer be parallel to the conduit axis, and direct coupling of acoustic waves into the ground is possible. The models presented herein focus only on the longitudinal resonances of the magma. From equation (B2) of Appendix B, the moment tensor amplitude for the explosion source, $M_{0}$, is given by

$$
M_{0} \propto \frac{\rho_{1} c_{1}}{\rho_{w} c_{s w}^{2}}
$$

where $\rho_{w}$ is the wall density and $c^{2}$ is the square of the shear wave speed of the conduit wall at that section. For the Pavlof model the following densities and shear wave velocities were used for each segment shown in Figure 5: $\rho_{w}=2700 \mathrm{~kg} / \mathrm{m}^{3}$ for all sections, $c_{s w 1}=2700 \mathrm{~m} / \mathrm{s}$, and $c_{s w 2}=c_{s w 3}=200 \mathrm{~m} / \mathrm{s}$. The low shear wave velocity of the deeper two layers may be explained by the molten state of the conduit interior. The magma conduit wall presents a no-slip condition to the fluid flow (so that the particle velocity must vanish at the wall), and in this boundary layer the immobile melt may present a low shear wave velocity layer that acts as the effective acoustic wall of the conduit. The high shear wave velocity of the uppermost section may be due to two effects. First, above the $50 \%$ void fraction level, the gas-rich melt may have cooled significantly, and thus the conduit walls may have hardened and welded. Second, Garces and McNutt [1997] model the vent as a pressure-release surface (where the acoustic pressure is zero), and thus this interface acts as an excellent reflector of sound. In reality, the vent has a radiation impedance which permits a greater loss of energy into the atmosphere, and thus less energy is trapped in the conduit. The addition of an impedance condition at the vent to the aforementioned model may rearrange the partitioning of energy and permit a lower value for the shear wave velocity of the conduit wall.

Expressions for the evaluation of the acoustic and seismic fields radiated by fluid flow through a magma conduit (Figure 5) are given by Garces [1997]. Garces and McNutt [1997] obtained a Green's function solution for the acoustic field in the magma conduit and the atmosphere but did not provide solutions for the equivalent moment tensor for this configuration. Appendix B gives the paraxial approximation of the moment tensor for the model presented by Garces and McNutt [1997], using the formulation of Garces [1997]. Unless otherwise stated, the synthetic seismic traces were computed for the Rayleigh wave. The paraxial approximation is justified because the explosion source region proposed for
Pavlof is very shallow, and thus near-horizontal launch angles will dominate the resultant Rayleigh wave amplitude. For the evaluation of the seismic velocity synthetics, $\lambda=\mu, \rho_{\mathrm{g}}=2700$ $\mathrm{kg} / \mathrm{m}^{3}, c_{\mathrm{p}}=3000 \mathrm{~m} / \mathrm{s}, c_{\mathrm{s}}=1732 \mathrm{~m} / \mathrm{s}, r=8 \mathrm{~km}, \theta=\phi=\pi / 2$. The quality factors for $P, S$, and Rayleigh waves are $Q_{p}=300, Q_{s}$ $=175$, and $Q_{R}=45$, respectively; the first two are estimated and the latter value was measured by McNutt and Jacob [1986]. For the evaluation of the pressure wave synthetics an atmospheric sound speed $c=320 \mathrm{~m} / \mathrm{s}$ and an air density $\rho=1$ $\mathrm{kg} / \mathrm{m}^{3}$ were used.

\subsection{Coupling of the Air Wave into the Ground}

A wave propagating in the atmosphere can transmit energy into the ground, and this coupling is enhanced when the shear wave velocity of the ground surface is commensurate with the sound speed of the atmosphere. At Pavlof the seismic network recorded numerous explosion signals that were coupled from the atmosphere into the ground, and these signals were easily recognized by their propagation speed (Figures 2 and 3). The temporal variability of the ground-coupled explosion waveforms suggested that the temporal and spectral features of the explosions were not caused by site effects. In addition, explosion waveforms recorded by seismometers were remarkably similar to those recorded directly with lowfrequency pressure sensors at Stromboli [Garces, 1995], Arenal [Garces et al., 1998a], and Sakurajima Volcanoes [Iguchi and Ishihara, 1990; Garces et al., 1999], and we infer that the waveforms are representative of the conditions at the source. Thus it is necessary to extract the pressure amplitude from the seismic amplitude by investigating the transmission of sound waves into the ground. In volcanic environments, where loose tephra often covers the surrounding area, slow shear wave velocities can be easily encountered [Chouet et al., 1998]. A complete derivation of the reflection and transmission coefficients for plane waves impinging on an isotropic solid half-space is given by Brekhovskikh [1980]. These expressions are given in Appendix $\mathrm{C}$ and are utilized to determine the amplitude and phase of the acoustic pulse transmitted into the ground. The presence of surface and evanescent waves can also be extracted from the poles and branch points introduced by the integration of wavenumber space of the reflection and transmission coefficients. For the case of the Pavlof explosions the resemblance of air-wave signatures recorded by seismometers to acoustic pressure signatures recorded elsewhere, as well as their waveforms, spectra, and propagation velocities, suggest that these groundcoupled air waves could be adequately modeled by direct energy transmission of the air wave into the ground. Since acoustic energy impinging on the ground at these short ranges will be traveling close to the horizontal [Garces et al., 1998b], equation (C4) is utilized to estimate the vertical seismic velocity induced in the ground by a pressure wave arriving close to the grazing angle. The $P$ and $S$ wave velocities for the shallow loose tephra at station PS4 were taken to be 1500 and $380 \mathrm{~m} / \mathrm{s}$, respectively. These wave velocities are consistent with the values for the shallowest layers estimated by Chouet et al. [1998] at Stromboli, and we assumed the effective wave speeds are averaged over a wavelength.

\section{Discussion of Waveform Analysis}

All the model parameters have been specified in the sections $2-6$ and we now discuss the comparison between the 
(a) Pavlof tremor at station ps4z, 092996

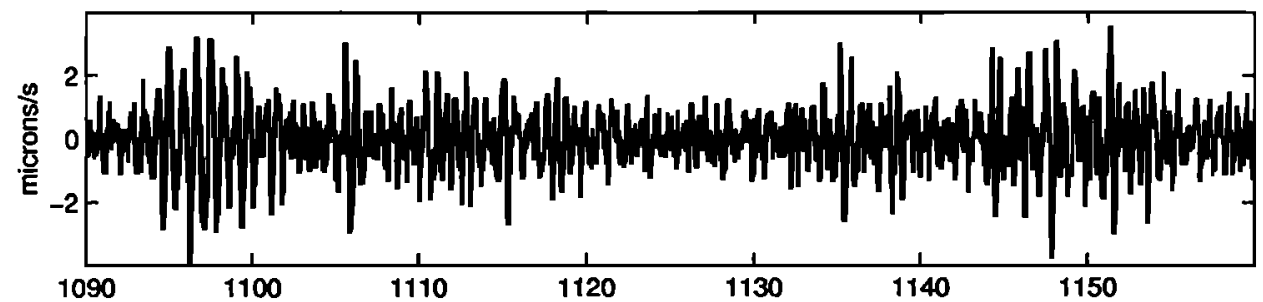

(b) Pavlof tremor synthetic, Rayleigh wave
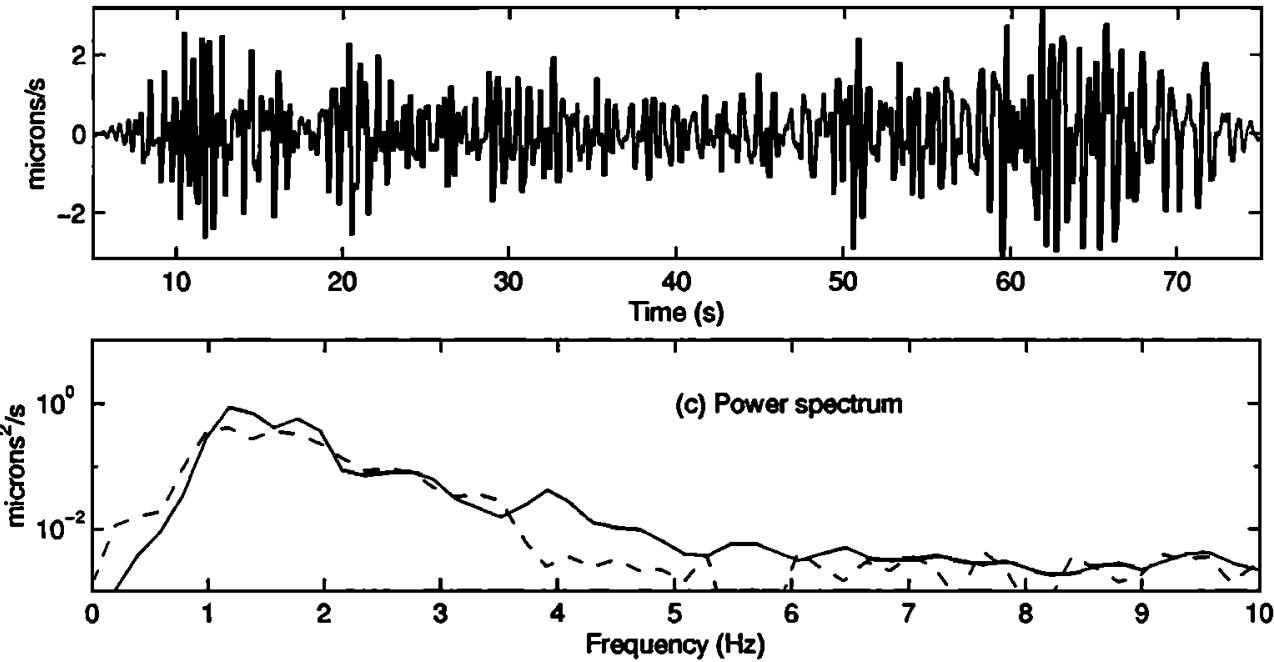

Figure 12. Comparison of (a) the seismic velocity synthetic with (b) the Pavlof tremor recorded at station PS4. Both spectra (c) were calculated by using a sliding $5.12 \mathrm{~s}$ Hanning window with $50 \%$ overlap. The amplitude envelopes should match, as the amplitude data from Figure 4 (bottom) was used to compute the amplitude of the source velocity function shown in Figure 10. The spectrum for the synthetic is shown as a dashed line. The spectra are well matched, suggesting that the tremor signal may be modeled by a resonant magma conduit driven by random oscillations in the magma flow. The $4 \mathrm{~Hz}$ spectral peak in the recorded data is a site effect and not replicated by the model.

theoretical and the observed waveforms. The tremor signals are relatively straightforward and are modeled as a random excitation (turbulent flow) which drives a linear oscillator (magma conduit). The comparison between the vertical particle velocity of Pavlof tremor and the model's results are shown in Figures 12a and 12b, respectively, and Figure 12c shows the comparison of theory and data in the frequency domain. The solid line shows the power spectrum for the Pavlof data; the peak at $4 \mathrm{~Hz}$ is attributed to a site response. The amplitude and frequency content of the theoretical and recorded signals match well, suggesting that the model of the Pavlof conduit may be reasonable. The amplitude envelope of the tremor signal shown in Figure 4 was used to compute the envelope of the synthetic (equation (11)); however, the spectrum was determined from the resonance characteristics of the melt in the conduit and is indicative of the gas content of the melt [Garces et al., 1998a]. This approach demonstrates the possible value of this model for eruption monitoring: the amplitude envelope of the tremor can be extracted in real time from the data, ingested by the VOLAR model, and utilized to interpret changes in the spectral content of the data as possible variations in the gas content of the melt. Since the seismic amplitude is partly dependent on the flow velocity, it may also be possible to track the amounts of material passing through the conduit, and predict ash cloud heights from the mass flux estimates (equation (4)).
The model predicts a pressure signal (Figure 13) that matches the amplitude envelope of the tremor signal but differs significantly in its spectral structure. The absolute amplitude of this signal is quite small and may be difficult to detect at this range because the signal level is likely to be below that of the ambient noise. To observe this signal, it would be necessary to place sensitive pressure sensors at a distance of a few hundred meters from the vent. The spectral content of the pressure wave has peaks characteristic of the shallowest section of the conduit. The low amplitude and the spectral content of the pressure wave illustrates the acoustic decoupling that occurs between the deeper and shallow parts of the magma conduit. This decoupling occurs because of the high contrast in acoustic impedance between the highly vesiculated melt at shallow depths and the deeper melt and suggests that acoustic waves may provide direct measurements of the highly variable region close to the fragmentation level. When direct pressure measurements are obtained in the vicinity of vigorous eruptions, it is possible to record pressure waves associated with magma flow and use them to obtain improved estimates of the physical properties of the melt [Hagerty et al., 1997].

The explosion signals present an interesting problem, as it is postulated that explosions occur in a highly variable and poorly understood region of highly vesiculated magma [Garces and Hansen, 1998]. The explosion signals consist of 


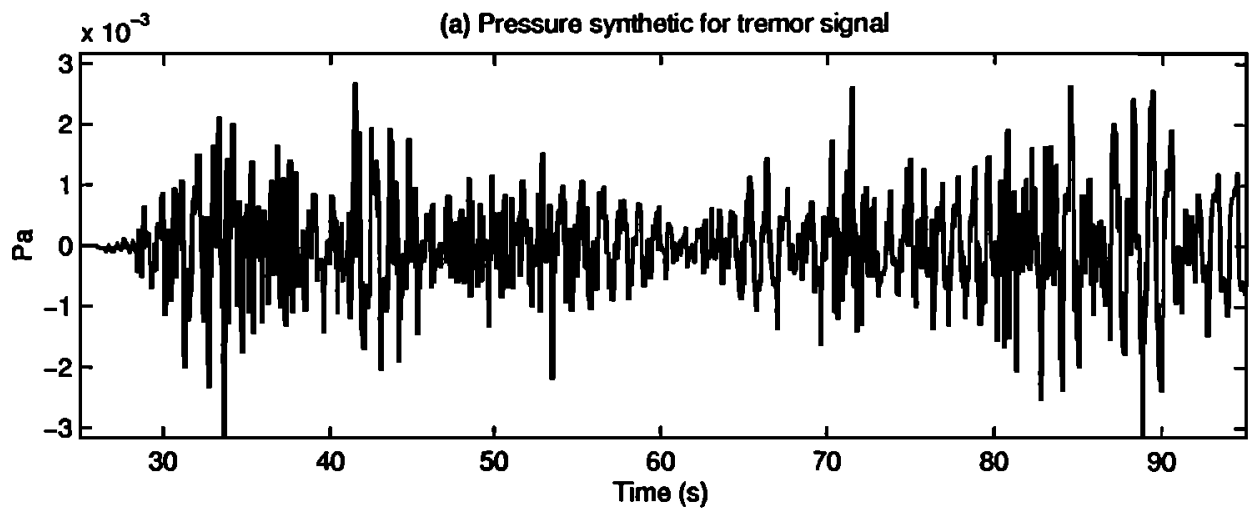

(b) Power spectrum for signal shown above

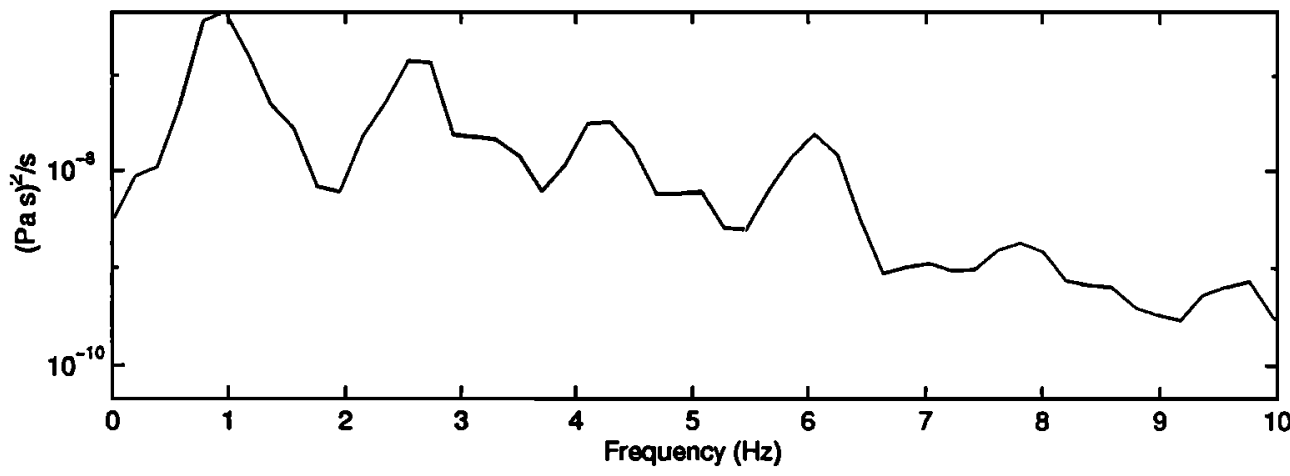

Figure 13. (a) Predicted time signature and (b) spectrum of the pressure signal accompanying the tremor. Note the spectral peaks characteristic of the shallowest conduit section and the small pressure amplitude.

a direct ground wave and a ground-coupled air wave. In this paper we propose that the ground wave signal is dominated by a fluid injection process, which either introduces gas-rich material into the conduit or detonates the metastable magmagas mixture. The other possible interpretation is that the ground wave corresponds to a direct wave triggered by the explosion and is altered by the propagation environment. This confronts us with the futility of using flat-layered models in a volcanic terrain which is highly irregular and heterogeneous, but the fact is that even if we had state-of-the-art threedimensional seismic wave propagation models, we presently lack detailed seismic velocity data for Pavlof volcano. That the topography will wreak havoc with our seismic waveforms is not in question. The main issue is whether the frequency bandwidth of the seismic waves is a reliable indicator of the source bandwidth. Site effects specific to each station appear as horizontal bands in spectrograms. However, the tremor energy peak near $2 \mathrm{~Hz}$ is common to all stations, and it is reasonable to infer that this energy band is radiated by the conduit. Thus we focus our analysis of direct seismic arrivals on matching the spectra of the recorded signals, acknowledging that the actual waveforms will be altered by the irregular topography of the volcanic edifice. However, we make an exception for the ground-coupled air wave, as this wave is thought to propagate in the atmosphere with minimal distortion until it is coupled into the ground right at the recording station.

We first consider the direct coupling of the explosion pulse into the ground by using the explosion source parameters given in section $\mathbf{5 . 2}$ and the magma conduit properties and dimensions discussed in sections $3,5.1$, and 6.1. Figure 14 shows the variation in the amplitudes of the direct explosion pulse and the ground-coupled air wave. The first pulse would correspond to the explosion waveform, and we attribute all subsequent arrivals to multiple reflections occurring within the reverberating uppermost layer of the magma conduit. All the conduit parameters are held fixed except the sound speed at the shallowest layer, which takes the values of 20,51 , and $200 \mathrm{~m} / \mathrm{s}$. The specific acoustic impedance of the overlying atmosphere is $\rho c=340 \mathrm{~kg} \mathrm{~m}^{-2} \mathrm{~s}^{-1}$, and it is evident that as the acoustic impedance of the melt approaches that of the atmosphere, more energy goes into the air than into the ground. As the melt impedance increases, the coupling from the magma into the ground increases, and the ground wave amplitude increases. If the direct explosion pulse can be identified, it may be possible to assess changes in the gas content of melt from the ratio of the air wave amplitude to the ground wave amplitude.

Figure 14b shows the predicted ground velocity for the direct arrival and the coupled air wave for the magma conduit parameters given in Tables 1-3. The theoretical ground wave suffers various inadequacies when compared to the recorded ground wave (Figure 15). The recorded ground wave has an emergent arrival, in contrast to the relatively sharp first motion of the synthetic trace. Note that the tremor frequency is still dominant in the recorded ground wave, albeit the spectra are enriched in higher frequencies. Although it is possible to construct a thin-layered structure that would be capable of dispersing the synthetic explosion waveform so that it resembled the recorded signal, it is unlikely that the same 
(a) Ground wave and air wave, $c 1=20 \mathrm{~m} / \mathrm{s}$

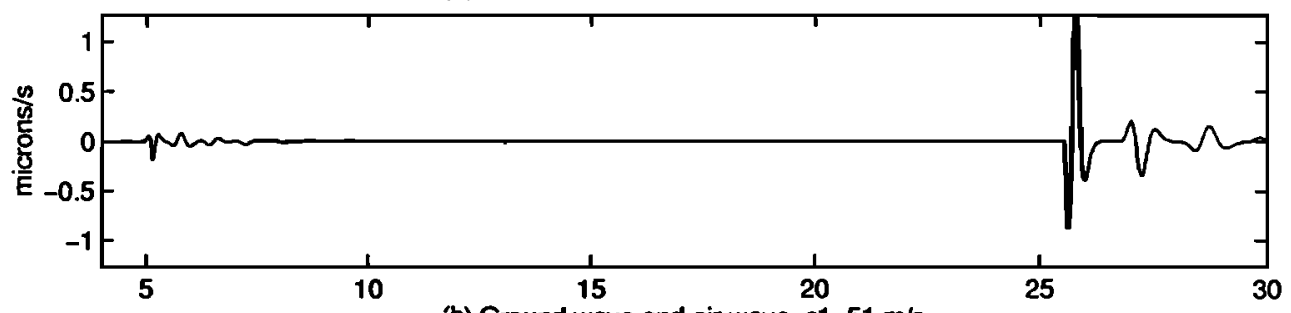

(b) Ground wave and air wave, c1 =51 m/s

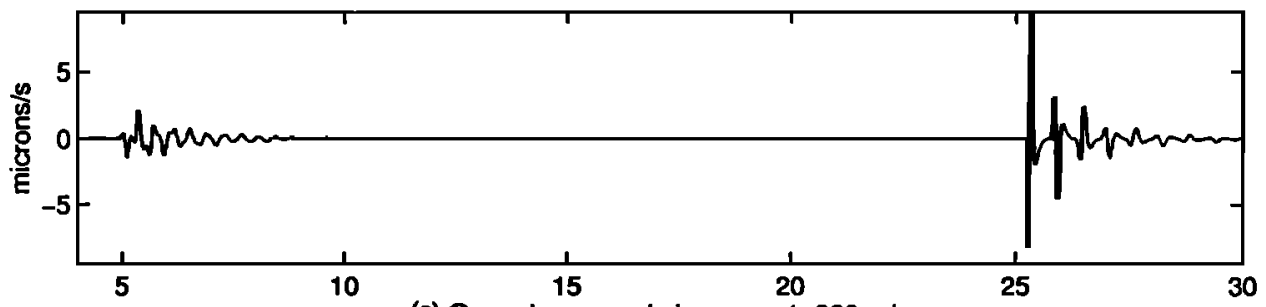

(c) Ground wave and air wave, c1=200 m/s

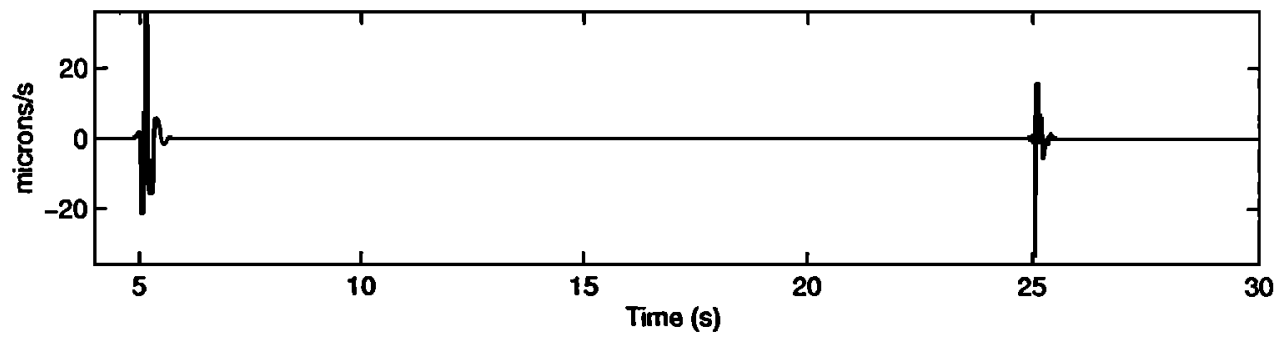

Figure 14. Comparison of Rayleigh wave amplitude and air wave amplitude for explosions inside a magma conduit with the same parameters given in Tables 1-3, except for the sound speed for the shallowest section: (a) $c_{1}=20 \mathrm{~m} / \mathrm{s}$, (b) $c_{1}=51 \mathrm{~m} / \mathrm{s}$, (c) $c_{1}=200 \mathrm{~m} / \mathrm{s}$. The sound speed determines the period of resonance of the conduit and the partitioning of the explosion energy between the air wave and the ground wave.

structure would be present at all stations in the seismic network.

A different hypothesis, consistent with observed seismic signals preceding explosions at Stromboli volcano, Italy [Garces, 1995; Chouet et al., 1998], can be invoked to explain the lower frequency content of the ground wave. At Stromboli, pressure pulses associated with explosions are preceded by low-frequency seismic signals which also have a dominant spectral peak characteristic of the tremor signals. These long-period events precede the observed explosion pressure by a time which is too long to justify by assuming that the seismic signal was generated by the same source process that made the explosion pressure. These precursory signals may be attributed to a transition in the flow regime where gas-rich material is injected into the volcanic system. One possibility is that the explosions are due to the violent expansion of the injected gas-rich material as it reaches the shallow parts of the magma conduit. Another possibility is that the pressure waves associated with the mass injection trigger the metastable magma-gas mixture already residing in the highly vesiculated region above the $50 \%$ void fraction. One can conceive a heterogeneous mixture where a dense premixture of magma and water may absorb the energy from the incident pressure waves and accumulate it until a critical threshold is reached, whereupon the mixture is detonated. This critical energy produced by an incident pressure wave is characteristic of most chemical explosives and known as the critical energy fluence [Cooper and Kurowski, 1966]. Since the relaxation time of the melt around the $50 \%$ void fraction level may be close to the periods of excitation from the pressure waves, the melt may possess a memory and thus be capable of storing elastic energy until it reaches the detonation threshold.

The fact that explosion source mechanism is poorly understood (section 5.2) forces us to adopt a phenomenological approach to the modeling of the explosion signals. The source injection model of Figure 8 was used to generate a synthetic long-period signal, and the direct ground wave (Figure 14b) from the explosion was added to this longperiod event to create the seismic velocity trace and the spectrum shown in Figure 16 (left). The long-period event was shifted by $2 \mathrm{~s}$ ahead of the direct wave before superposing both signals. The direct ground wave is smaller than the longperiod event and appears as an unobtrusive high-frequency break in the waveform. The emergent phase, the dominant tremor frequency, and the increase in energy above $5 \mathrm{~Hz}$ are matched in the synthetic and recorded signals, although the fine structure of the recorded spectrum is not well replicated by the synthetic. This is expected, given the simplicity of the wave propagation model used to compute the theoretical waveforms.

Figure 16 (right) shows the ground-coupled air wave shown in Figure 14b. Figure 17 further compares the theoretical and recorded air phase in the time and frequency domains and shows an acceptable match between the waveforms. The higher-frequency spectral peaks are not well 

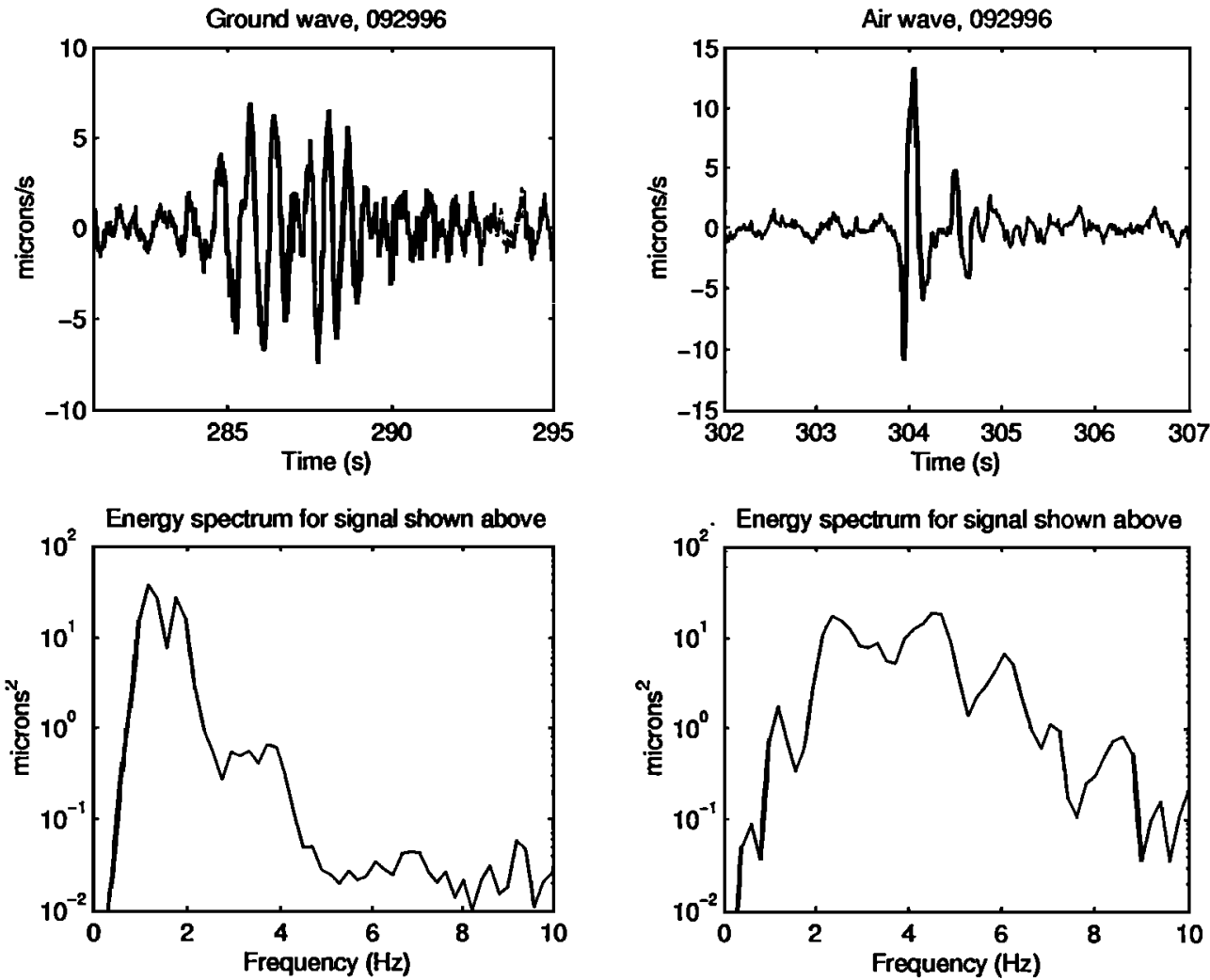

Figure 15. Waveforms and spectra for the ground wave and the air wave of explosion signals recorded at station PS4. Note that the waveform characteristics and spectral content of these two signals is quite dissimilar. The spectra are calculated by using a sliding $5.12 \mathrm{~s}$ Hanning window with $50 \%$ overlap.
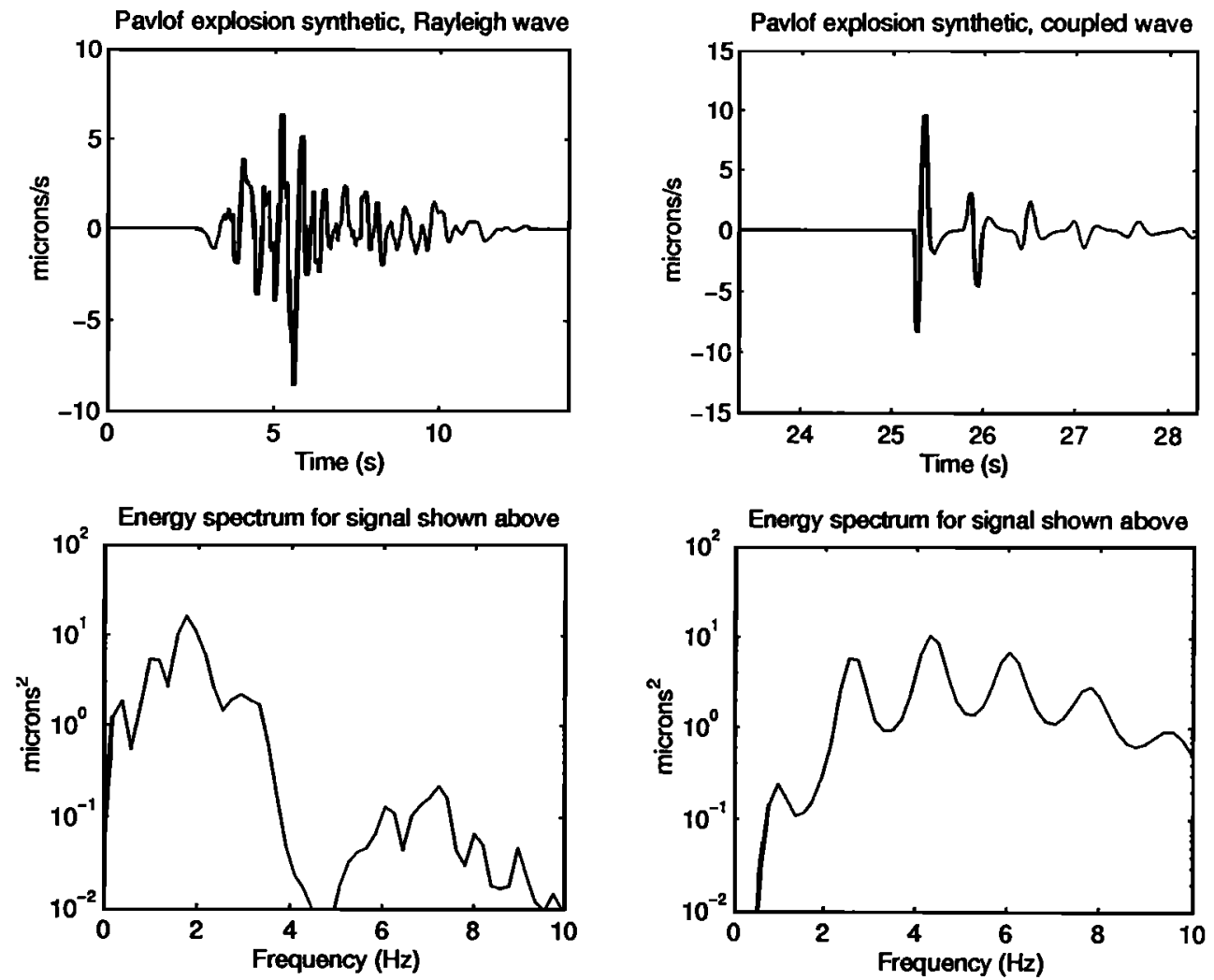

Figure 16. Synthetic waveforms and spectra for the ground wave and the air wave. The spectra were computed using the same sampling rate and method used in Figure 15. The ground wave is modeled as a superposition of a mass injection process and the direct wave from the explosion shown in Figure 14b. The air wave is obtained from the coupling of the airborne pressure wave into the ground. 

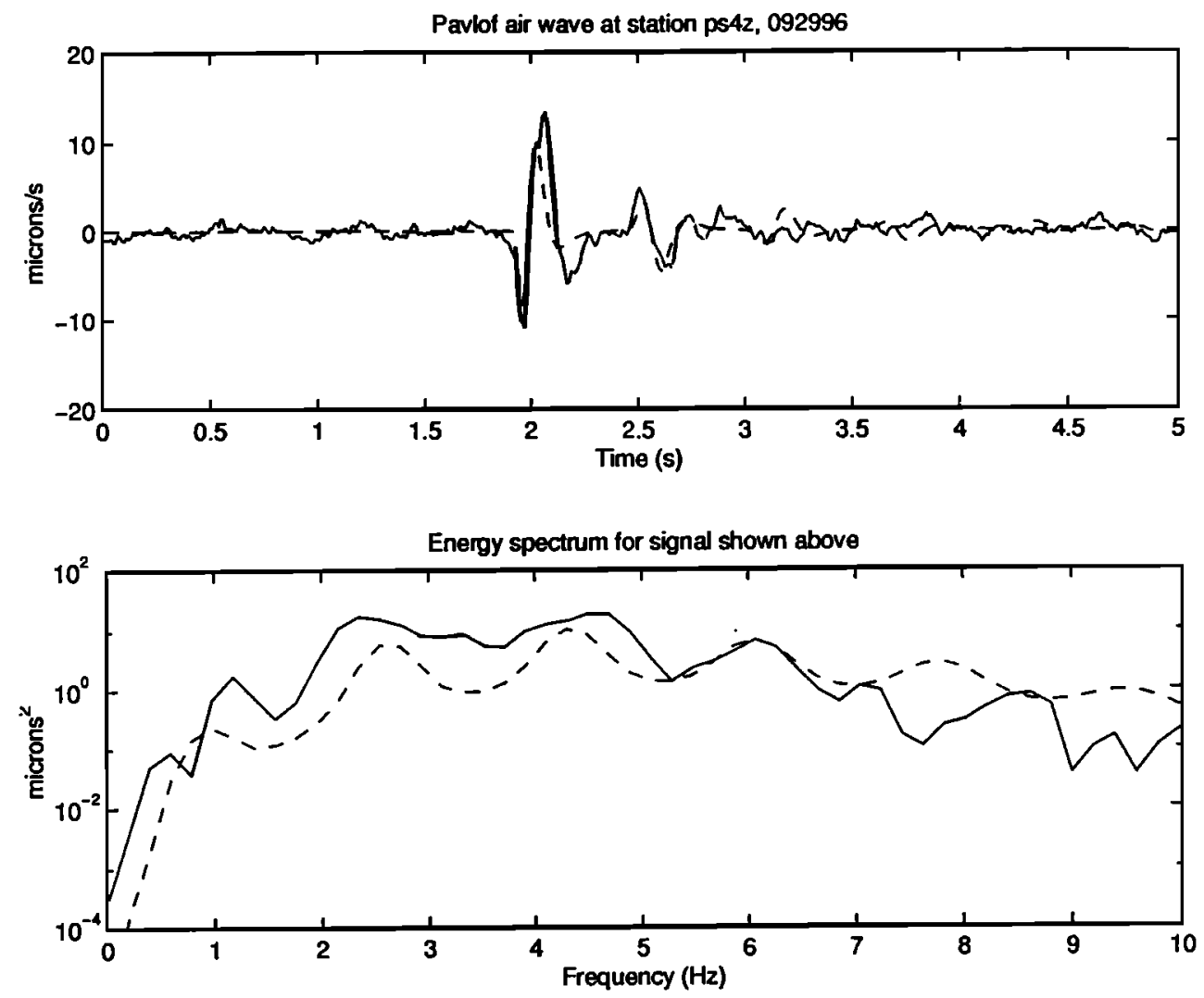

Figure 17. Comparison of the time signatures and spectra of the synthetic (dashed line) and recorded (solid line) air wave at Pavlof. The synthetic waveform mimics the principal features of the air wave, and the match between theory and data is reasonable for frequencies lower than $6 \mathrm{~Hz}$. The deterioration of the fit at higher frequencies may be due to the presence of transverse conduit resonances in the upper part of the conduit.

matched by the synthetic spectra, and this may be due to the presence of transverse resonant modes in the conduit [Buckingham and Garces, 1996]. Since we are only addressing those effects attributed to the longitudinal modes, these higher frequencies are beyond the scope of this paper. However, the dominant features of the waveform are well matched by considering only the longitudinal resonances. We can anticipate this from looking at the spectra of the recorded signal, since there is at least an order of magnitude difference in the power of the spectral peak at $2 \mathrm{~Hz}$ and the power of the peak at $8 \mathrm{~Hz}$.

The match between theory and the data suggests that the linear source and wave propagation models that we have utilized to generate our synthetic signals are adequate. We can improve the accuracy of our estimates and the quality and breadth of our models, but our results suggest that the acoustic resonance of magma conduits explains the salient temporal and spectral characteristics of seismic and acoustic signals radiated during Strombolian volcanic eruptions. The total run time for the models presented herein (using a total synthetic record length of $120 \mathrm{~s}$ and a sampling rate of $100 \mathrm{~Hz}$ ) is $<90 \mathrm{~s}$ in a Sun Ultra 1, and with efficient coding, the run times can be further shortened. The celerity of the computations is due to the fact that the models are evaluated from exact analytical expressions. Efficient construction of algorithms for iterating the input parameters of the VOLAR model may lead to nearreal time waveform analysis of seismo-acoustic signals, which may permit estimates of composition changes in the melt, fluid flow variations, and ash cloud heights during volcanic eruptions.

\section{Concluding Remarks}

The synergy of fluid dynamic, acoustic, and seismic processes in volcanic systems has been exploited to extract estimates of the melt properties and magma conduit geometry of Pavlof volcano. The model results match available seismic data and visual observations, and thus we claim a degree of success in our endeavor. Future models will have to address in more detail the physics of volcanic explosions, the coupling of acoustic waves in magma into the ground and atmosphere, and the behavior of moving, unstable foams. It is our hope that improved models of the coupled magma-groundatmosphere system will permit more precise estimates of the physical and chemical properties of volcanic interiors and that our ability to obtain better experimental data will justify the improved accuracy of our models.

\section{Appendix A: Void Fractions of $\mathrm{H}_{2} \mathrm{O}$ and $\mathrm{CO}_{2}$ in Magma-Gas Mixtures}

The void fraction is a critical variable in the determination of the seismo-acoustic parameters of the melt, as it affects the viscosity, sound speed, density, and relaxation time of the multiphase mixture. This appendix derives expressions for the void fractions of $\mathrm{H}_{2} \mathrm{O}$ and $\mathrm{CO}_{2}$ as functions of pressure and the initial mass fractions of these components in the melt. 
The mass $M$ of a parcel of fluid is

$$
M=M_{1}+M_{\mathrm{H}_{2} \mathrm{O}}+M_{\mathrm{CO}_{2}}
$$

where the terms on the right hand side correspond to the mass of liquid, water, and carbon dioxide, respectively. The total mass of the $\mathrm{H}_{2} \mathrm{O}$ and $\mathrm{CO}_{2}$ components will be divided into that fraction which is in solution and that fraction which has come out as gas. This can be expressed as

$$
\begin{aligned}
& M_{\mathrm{H}_{2} \mathrm{O}}=x_{1} M+M_{z 1} \\
& M_{\mathrm{Co}_{2}}=x_{2} M+M_{z^{2}}
\end{aligned}
$$

where $x_{1}$ and $x_{2}$ are the solubilities (in mass fraction) and $M_{g 1}$ and $\mathrm{Mg}_{2}$ are the gas mass of $\mathrm{H}_{2} \mathrm{O}$ and $\mathrm{CO}_{2}$ in that parcel of fluid. The initial mass fractions of these compounds is

$$
x_{1}^{0}=\frac{M_{\mathrm{H}_{2} \mathrm{O}}}{M}, \quad x_{2}^{0}=\frac{M_{\mathrm{CO}_{2}}}{M},
$$

and $P_{t 1}$ and $P_{i 2}$ are the pressures at which $\mathrm{H}_{2} \mathrm{O}$ and $\mathrm{CO}_{2}$ begin to come out of solution, with $P_{11}<P_{12}$. When the ambient pressure $P$ is such that $P>P_{12}$,

$$
M=M_{1}+x_{1}^{0} M+x_{2}^{0} M
$$

and thus

$$
M_{1}=M\left[1-\left(x_{1}^{0}+x_{2}^{0}\right)\right] .
$$

Combining the general expression (A1) for the mass at a pressure $P<P_{t 1}$ with (A5b) yields

$$
M \Delta X=M_{g 1}+M_{g^{2}}
$$

where

$$
\Delta X=\left(x_{1}^{0}+x_{2}^{0}\right)-\left(x_{1}+x_{2}\right) \text {. }
$$

The volume $V$ and mass of a fluid parcel are given by

$$
\begin{gathered}
V=V_{1}+V_{g 1}+V_{D 1}+V_{g 2}+V_{D 2}, \\
M=\rho_{1} V_{1}+\rho_{g 1} V_{g 1}+\rho_{D 1} V_{D 1}+\rho_{g 2} V_{g 2}+\rho_{D 2} V_{D 2},
\end{gathered}
$$

where $V_{D 1}$ and $V_{D 2}$ are the total volumes of dissolved $\mathrm{H}_{2} \mathrm{O}$ and $\mathrm{CO}_{2}$ in the fluid parcel and $\rho$ denotes the density of each component. The contributions to the total volume from $V_{D 1}$ and $V_{D 2}$ can be neglected because they are initially small and will only get smaller as more gas comes out of solution. Then

$$
\begin{gathered}
V=V_{1}+V_{g 1}+V_{g 2}, \\
M=\rho_{1} V_{1}+\rho_{g 1} V_{g 1}+\rho_{g 2} V_{g 2} .
\end{gathered}
$$

Combining (A6) and (A9b),

$$
\Delta X \rho_{1} V_{l}=\rho_{g 1} V_{g 1}(1-\Delta X)+\rho_{g 2} V_{g 2}(1-\Delta X),
$$

and using (A9a) yields

$$
\left|\rho_{g}(1-\Delta X)+\rho_{1} \Delta X\right| \alpha_{1}+\left[\rho_{g 2}(1-\Delta X)+\rho_{1} \Delta X \mid \alpha_{2}=\rho_{1} \Delta X\right.
$$

where

$$
\alpha_{1}=\frac{V_{g 1}}{V}, \quad \alpha_{2}=\frac{V_{g 2}}{V}
$$

are the void fractions of $\mathrm{H}_{2} \mathrm{O}$ and $\mathrm{CO}_{2}$ gas, respectively. Note that for $P_{2 r}>P>P_{l l}, \alpha_{l}=0, x_{1}^{0}-x_{1}=0$, and

$$
\alpha_{2}=\frac{\rho_{1}\left(x_{2}^{0}-x_{2}\right)}{\rho_{g 2}\left[1-\left(x_{2}^{0}-x_{2}\right)\right]+\rho_{1}\left(x_{2}^{0}-x_{2}\right)},
$$

equation (A13) is consistent with the results of Jaupart and Tait [1990], who approximated the first term in the denominator to $\rho_{\mathrm{g} 2}$.

For $P<P_{l i}, H_{2} O$ comes out of solution. We can then use the ideal gas law to determine the volume of a certain quantity of gas at a pressure $P$

$$
V_{g 2}=n_{2}^{g} \frac{R T}{P}=\frac{n_{2}^{g}}{n_{1}^{g}}\left[n_{1}^{g} \frac{R T}{P}\right]=\frac{n_{2}^{g}}{n_{1}^{g}} V_{g 1}=\frac{M_{g 2}}{M_{g 1}} \frac{m_{1}}{m_{2}} V_{g 1}
$$

or, expressing in terms of mass and void fractions

$$
\alpha_{2}=\frac{\left(x_{2}^{0}-x_{2}\right)}{\left(x_{1}^{0}-x_{1}\right)} \frac{m_{1}}{m_{2}} \alpha_{1},
$$

where $m_{1}$ is the molar mass of water $(18 \mathrm{~g} / \mathrm{mol})$ and $m_{2}$ is the molar mass of $\mathrm{CO}_{2}(44 \mathrm{~g} / \mathrm{mol})$. Let

$$
s=\frac{\left(x_{2}^{0}-x_{2}\right)}{\left(x_{1}^{0}-x_{1}\right)} \frac{m_{1}}{m_{2}} .
$$

Then substituting (A15) into (A11) yields the final for the void fraction as a function of the gas solubilities

$$
\begin{gathered}
\alpha_{1}=\frac{\rho_{l} \Delta X}{\left(\rho_{g 1}+s \rho_{g^{2}}\right)(1-\Delta X)+\rho_{l} \Delta X(1+s)} \\
\alpha_{2}=s \alpha_{1} .
\end{gathered}
$$

The solubility of $\mathrm{H}_{2} \mathrm{O}$ as a function of pressure in rhyolitic melts is given by Tait et al.[1989]

$$
x_{1}=4.11 \times 10^{-6} P^{05}
$$

and in mafic magma

$$
x_{1}=6.8 \times 10^{-8} P^{07} \text {. }
$$

The solubility of $\mathrm{CO}_{2}$ as a function of pressure in basaltic melt is

$$
x_{2}=4.4 \times 10^{-12} P \text {. }
$$

Equations (A15) to (A21) allow us to compute the void fractions of water and carbon dioxide in silicate melts as a function of pressure. It is understood that more complicated relationships between the solubilities of $\mathrm{H}_{2} \mathrm{O}$ and $\mathrm{CO}_{2}$ may be present in ryolitic melts at high $\mathrm{H}_{2} \mathrm{O}$ mass fractions and high pressures [Anderson, 1989], and that other formulations exist for the computation of gas solubility curves [Papale, 1996], but the estimates given by (A19)-(A21) will be appropriate for the low gas mass fractions and low pressures investigated in this paper. Future versions of the present models will incorporate improved formulations of the geochemical properties of silicate melts.

The gas densities are estimated from the ideal gas law

$$
\rho_{g}=\frac{P m_{g}}{R T}
$$

where $m_{g}$ is the weight per mole of the gas. If lithostatic pressure is assumed, then

$$
P=10^{5} \mathrm{~Pa}+\rho_{s} g z
$$

where $\rho_{s}$ is the rock density and $z$ is depth. Then it is possible to construct profiles for the void fraction and its related quantities as functions of depth and investigate the changes in the acoustic properties of the melt as functions of melt composition. 


\section{Appendix B: Moment Tensor for a Shallow Conduit}

Using equation (31) of Garces [1997] to integrate equation (18) of Garces and McNutt [1997], the equivalent moment tensor for an explosive source in a rectangular crack of width $W$, cross-sectional are $S_{1}$, and length $L_{1}$ is given by

$$
M=M_{o}\left[\begin{array}{lll}
1 & 0 & 0 \\
0 & 3 & 0 \\
0 & 0 & 1
\end{array}\right]
$$

where

$$
\begin{aligned}
M_{0}= & \mu \frac{j \rho_{1} c_{1}}{k_{1} S_{1}} \frac{3 \pi W^{2}}{16 \mu_{w}} Q \frac{1}{\hat{Z} \cos k_{1} L_{1}+j \sin k_{1} L_{1}} \\
& \times\left\{\hat{Z}\left[\cos k_{1}\left(L_{1}-z^{\prime}\right)-\cos k_{1}\left(L_{1}-2 z^{\prime}\right)\right]\right. \\
& \left.+j\left[\sin k_{1}\left(L_{1}-z^{\prime}\right)-\sin k_{1}\left(L_{1}-2 z^{\prime}\right)-\sin k_{1} z^{\prime}\right]\right\}
\end{aligned}
$$

and

$$
\hat{Z}=\frac{\rho_{2} c_{2}}{\rho_{1} c_{1}} \frac{S_{1}}{S_{2}} .
$$

The multiplicative factor $\mathbf{Q}$ is the explosive source strength, given in Garces and McNutt [1997].

\section{Appendix C: Transmission Coefficients for a Fluid Half-space over a Solid Half-space}

The solution for the particle velocities in the ground for a plane sound wave incident at an angle $\theta$ to the vertical, with pressure amplitude

$$
p=p_{0}\left\{e^{-j \alpha x}+V e^{j \alpha x}\right\} \exp j(\xi x-\omega t)
$$

is

$$
\begin{aligned}
& v_{1 x}=\frac{p_{0}}{\rho \omega}\left\{\xi W_{L} e^{-\jmath \beta_{1} z}+\beta_{1} W_{T} e^{-\jmath \beta_{1} z}\right\} \exp j(\xi x-\omega t) \cos \phi, \\
& v_{1 y}=\frac{p_{0}}{\rho \omega}\left\{\xi W_{L} e^{-\jmath \beta_{1} x}+\beta_{1} W_{T} e^{-\jmath \beta_{1} z}\right\} \exp j(\xi x-\omega t) \sin \phi, \\
& v_{1 x}=\frac{p_{0}}{\rho \omega}\left\{-\alpha_{1} W_{L} e^{-\jmath a_{1} z}+\xi W_{T} e^{-\jmath \beta_{1} z}\right\} \exp j(\xi x-\omega t) .
\end{aligned}
$$

In (C1) to (C4), the the reflection coefficient $V$ and the longitudinal $W_{L}$ and transverse $W_{T}$ transmission coefficients are

$$
\begin{aligned}
& V=\frac{Z_{L} \cos ^{2} 2 \gamma_{1}+Z_{T} \sin ^{2} 2 \gamma_{1}-Z}{Z_{L} \cos ^{2} 2 \gamma_{1}+Z_{T} \sin ^{2} 2 \gamma_{1}+Z} \\
& W_{L}=-\frac{c_{1}}{c} \frac{\cos \theta \cos 2 \gamma_{1}}{\cos \theta_{1}}(V-1) \\
& W_{T}=\frac{2 \sin ^{2} \gamma_{1}}{\tan \theta}(V-1),
\end{aligned}
$$

where

$$
Z=\frac{\rho c}{\cos \theta}, \quad Z_{L}=\frac{\rho_{1} c_{1}}{\cos \theta_{1}}, \quad Z_{T}=\frac{\rho_{1} b_{1}}{\cos \gamma_{1}}
$$

Acknowledgments. Many thanks to Kent Lindquist for reviewing this manuscript with a physicist's eye, and for stimulating discussions on operational definitions. John Benoit provided valuable improvements to the text, and perceptive field observations on the scaling relationships of large Aleutian brown bears. Three anonymous reviewers helped to improve the clarity and succinctness of the manuscript, for which we are grateful. This work was supported by the Alaska Volcano Observatory and by the state of Alaska.

\section{References}

Alidibirov, M., and D. Dingwell, Magma fragmentation by rapid decompression, Nature, 380, 146-148, 1996.

Anderson, A., S. Newnan, S. Williams, T. Druitt, C. Skirius, and E. Stolper, $\mathrm{H}_{2} \mathrm{O}, \mathrm{CO}_{2}, \mathrm{Cl}$, and gas in Plinian and ash-flow Bishop rhyolite, Geology, 17, 221-225, 1989.

Benoit, J., S. McNutt, M. Garces, and R. Hansen, Volcanic tremor and ground-coupled air-wave observations of the 1996 eruptions of Pavlof volcano, Alaska, and their implications for source location (abstract), Eos Trans. AGU, 78 (46), Fall Meet. Suppl., 430, 1997.

Brekhovskikh, L. M. Waves in Layered Media, Academic, San Diego, Calif, 1980.

Buckingham, M .J., and M. A. Garces, A canonical model of volcano acoustics, J. Geophys. Res., 101, 8129-8151, 1996.

Chouet, B., P. Dawson, G. DeLuca, M. Martini, G. Milana, G. Saccorotti, and R. Scarpa, Array analyses of seismic wave fields radiated by eruptive activity at Stromboli volcano, Italy, report, CNR-Gruppo Naz. per la Vulcanol., Felici Editore, Pisa, 1998.

Cooper, P., and S. Kurowski, Introduction to the Technology of Explosives, John Wiley, New York, 1966.

Garces, M. A., The acoustics of volcanic explosions, Ph.D. thesis, Univ. of Calif., San Diego, 1995.

Garces, M. A., On the volcanic waveguide, J. Geophys. Res., 102, 22,547-22,564, 1997.

Garces, M. A., and S. R. McNutt, Theory of the sound field generated by a resonant magma conduit, $J$. Volcanol. Geotherm. Res., 78, 155-178, 1997.

Garces, M. A., and R. A. Hansen, Waveform analysis of seismoacoustic signals radiated during the fall eruption of Pavlof volcano, Alaska, Geophys. Res. Lett., 25, 1051-1054, 1998.

Garces, M. A., M. T. Hagerty, and S. Y. Schwartz, Magma acoustics and time-varying melt properties at Arenal Volcano, Costa Rica, Geophys. Res. Lett., 25, 2293-2297, 1998 a.

Garces, M. A. R. A. Hansen, and K. Lindquist, Travel times for infrasonic waves propagating in a stratified atmosphere. Geophys. J. Int., 135, 255-263, 1998 b.

Garces, M., M. Iguchi, K. Ishihara, M. Morrissey, Y. Sudo, and T. Tsutsui, Infrasonic precursors to a Vulcanian eruption at Sakurajima volcano, Japan, Geophys. Res. Lett., 26, 2537-2540, 1999.

Graff, K. F., Wave Motion in Elastic Solids, Dover, Mineola, New York, 1991

Hagerty, M., S. Y. Schwart, M. Protti, M. Garces, and T. Dixon, Observations at Costa Rican volcano offer clues to causes of eruptions, Eos Trans. $A G U, 78,565,570-571,1997$.

Iguchi, M., and K. Ishihara, Comparison of earthquakes and air shocks accompanied with explosive eruptions at Sakurajima and Suwanosejima Volcanoes, Annu. Disaster Prev. Res. Inst., 33B-1, $1-12,1990$.

Jaupart, C., and S. Tait, Dynamics of eruptive phenomena, Rev. Mineral., 24, 213-236, 1990.

Kamo, K., K. Ishihara, and M. Tahira, Infrasonic and seismic detection of explosive eruptions at Sakurajima Volcano, Japan, and the PEGASAS-VE early-warning system, in Proceedings of the First International Symposium on Volcanic Ash and Aviation Safety, U. S. Geol. Surv. Bull. 2047, 357-365, 1994.

Lighthill, J., Waves in Fluids, Cambridge Univ. Press, New York, 1978.

McNutt, S. R., Volcanic tremor, in Encyclopedia of Earth System Science, vol.4, pp. 417-425, Academic, San Diego, Calif., 1992.

McNutt, S. R., Observations and analysis of b-type earthquakes, explosions, and volcanic tremor at Pavlof volcano, Alaska, Bull. Seismol. Soc. Am., 76, 153-175, 1986.

McNutt, S. R., Volcanic tremor at Pavlof volcano, Alaska, October 1973-April 1986, Pure Appl. Geophys., 125, 1051-1077, 1987.

McNutt, S. R., and R. J. Beavan, Eruptions of Pavlof volcano and their possible modulation by ocean load and tectonic stresses, $J$. Geophys. Res., 92, 11,509-11,523, 1987. 
McNutt, S. R., and K. H. Jacob, Determination of large-scale velocity structure of the crust and upper mantle in the vicinity of Pavlof volcano, Alaska, J. Geophys. Res., 91, 5013-5022, 1986.

Morse, P., and U. Ingard, Theoretical Acoustics, Princeton Univ. Press, Princeton, N.J., 1986.

Murase, T., and A. McBirney, Properties of some common igneous rocks and their melts at high temperatures, Geol. Soc. Am. Bull., 84, 3563-3592, 1973.

Neal, T., Pavlof volcano darkens the Alaskan sky, Eos Trans. $A G U$, 77, 519-520, 1996

Oppenheim, A. V., and R. W. Schafer, Discrete-Time Signal Processing, Prentice Hall, Englewood Hills, N.J., 1989.

Papale, P., Modeling of the solubility of a two-component $\mathrm{H}_{2} \mathrm{O}+\mathrm{CO}_{2}$ fluid in silicate liquids, VSG Rep. 96-I, pp. 1-36, Volcano Simul. Group, Pisa, Italy, 1996.

Papale, P., and F. Dobran, Magma flow along the volcanic conduit during the Plinian and pyroclastic flow phases of the May 18, 1980, Mount St. Helens eruption, J. Geophys. Res., 99, 43554373, 1994

Simkin, T., and L. Siebert, Volcanoes of the World, Geosci. Press, Tucson, Ariz., 1994.

Sparks, $R$., The dynamics of bubble formation and growth in magmas: A review and analysis, $J$. Volcanol. Geotherm. Res., 3, 1-37, 1978
Tahira, M., A study of the infrasonic wave in the atmosphere II. Infrasonic waves generated by the explosions of the Volcano Sakurajima, J. Meteorol. Soc. Jpn., 60, 896-907, 1982.

Tait, S., C. Jaupart, and S. Vergniolle. Pressure, gas content and eruption periodicity of a shallow, crystallizing magma chamber. Earth Planet. Sci. Lett., 92, 107-123, 1989.

Wilson, L., R. Sparks, T. Huang, and N. Watkins, The control of volcanic column heights by eruption energetics and dynamics, $J$. Geophys. Res., 83, 1829-1836, 1978.

J. Eichelberger, R. Hansen, and S. McNutt, Alaska Volcano Observatory, Geophysical Institute, University of Alaska, Fairbanks, 903 Koyukuk Drive, P.O. Box 757320, Fairbanks, AK 99775.

M. Garces, Infrasound Laboratory, Hawaii Institute of Geophysics and Planetology, University of Hawaii, Manoa, P.O. Box 1599, Kailua-Kona, HI 96745-1599. (milton@giseis.alaska.edu)

(Received September 4, 1997; revised January 13, 1999; accepted February 19, 1999.) 